\title{
MONITORING SAFETY CRITICAL INFRASTRUCTURE WITH MOBILE ROBOTS Plenary Keynote
}

TARIQ P. SATTAR

https://doi.org/10.1142/97898132310470004

\begin{abstract}
:
Reliable Non Destructive Testing (NDT) is vital to the integrity, performance management and sustainability of capital assets in safety critical industries such as oil and gas, aerospace, transportation, power generation and off-shore and subsea operations. The talk will highlight opportunities to improve the NDT of industrial structures and decrease the cost of inspection by automating the NDT with mobile robots. The challenge is to develop robots that can provide access to test sites and perform reliable NDT on very large vertical structures or structures located in hazardous environments thereby eliminating the large expense of erecting scaffolding or lengthy preparation for rope and platform access before inspection can start. The presentation will show climbing and swimming robots developed to detect weld and corrosion defects on ship hulls, floating platforms, mooring chains, petrochemical storage tanks, pressure vessels, concrete structures, wind blades and aircraft wings and fuselage. These developments provide the possibility of saving costs by reducing outage times or (where possible) carrying out the NDT in-service thus preventing expensive outages.
\end{abstract}


London South Bank University

\section{London} South Bank Innovation

Centre

\title{
Monitoring Safety Critical
}

\section{Infrastructure with Mobile}

\section{Robots}

\section{Opportunities and Challenges}

\author{
Tariq Sattar
}

TWI Chair and Director London South Bank Innovation Centre for Automation of NDT, 
London South Bank University
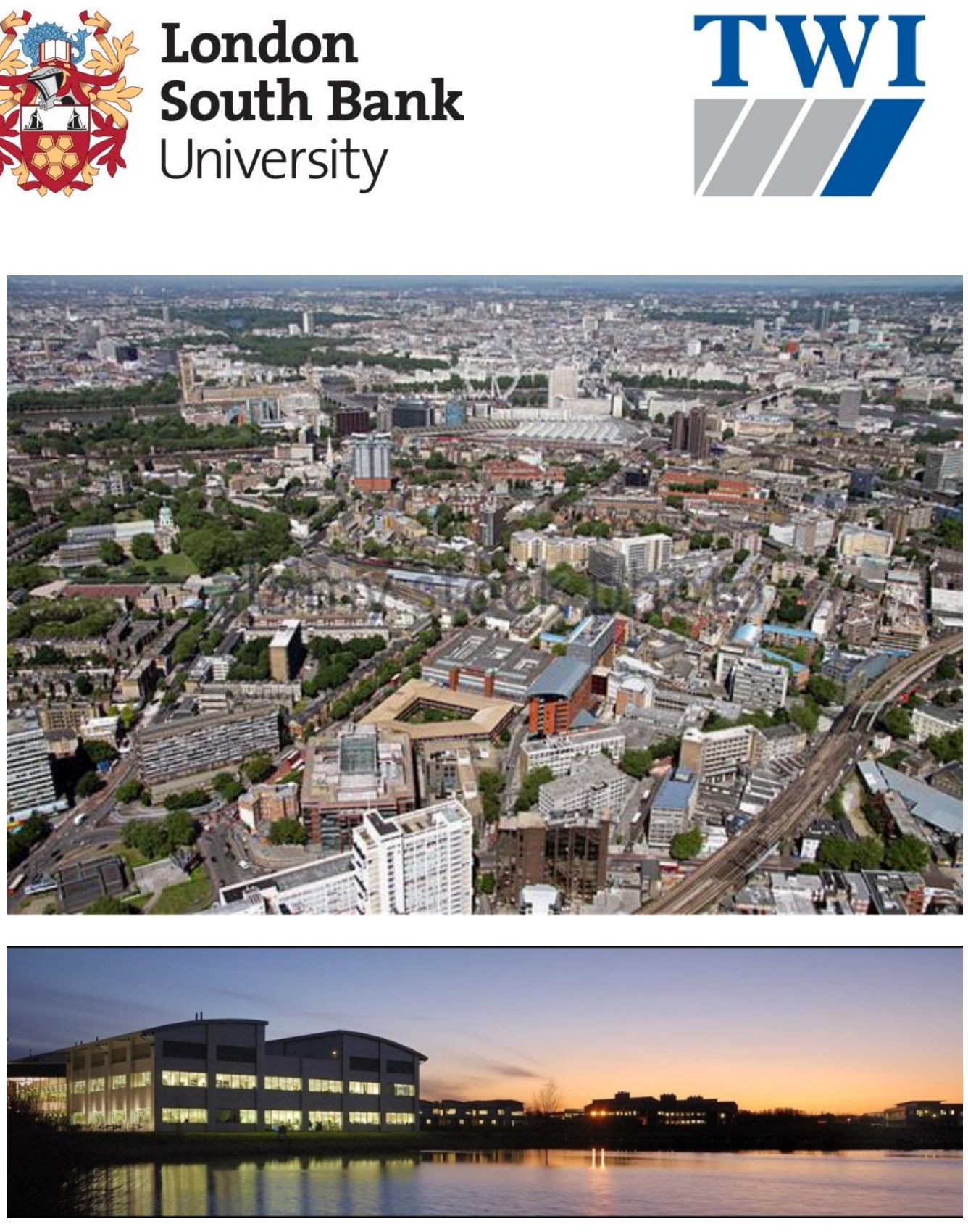

London South Bank Innovation Centre

London South Bank University, School of Engineering

Located on the South Bank of the river Thames, London

London South Bank Innovation Centre for Automation of NDT based in Granta Park, Great Abington, Cambridge CB2 6AL 


\section{Keynote organisation}

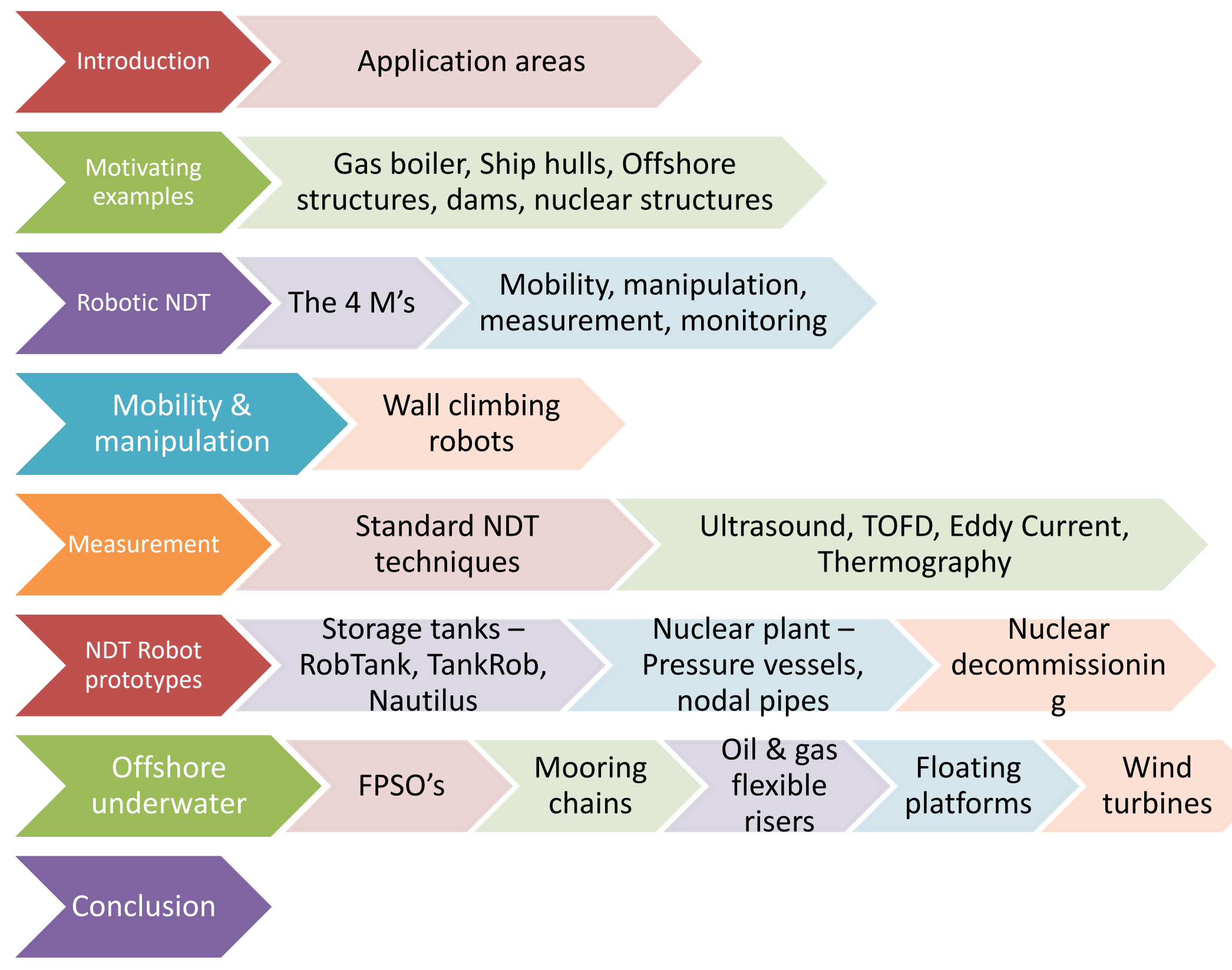




\section{INTRODUCTION}

Capital Assets in safety critical industries have the following characteristics:

1. Expensive assets require regular monitoring to

- ensure their safe operation

- acquire condition data to plan outages for maintenance

- extend life of asset.

2. Large structures with test sites at remote locations

3. Located in extreme and hazardous environments

4. Inspection requires an outage with pressure to reduce turn-around time
Oil and gas industries-

- Petrochemical storage tanks

- FPSO's - Floating platform storage of oil

- Flexible risers

- Mooring chains and lines

- Oil and gas platforms

- Pipelines

Nuclear power plants \& decommissioning

- Nozzle welds on pressure vessels and in primary circuit

- Radiation reprocessing cells

- Aerial stacks

- Concrete buildings

Renewable energy -

- Wind turbine towers and blades

- Tidal generator blades

- Off-shore monopiles for WTG's

- Dam walls in air and underwater

Transportation -

- Railway lines - cracks

- Aircraft - rivets, composite impact damage

- Ships - welds and corrosion 
Inspection of $90 \mathrm{~m}$ tall gas boiler

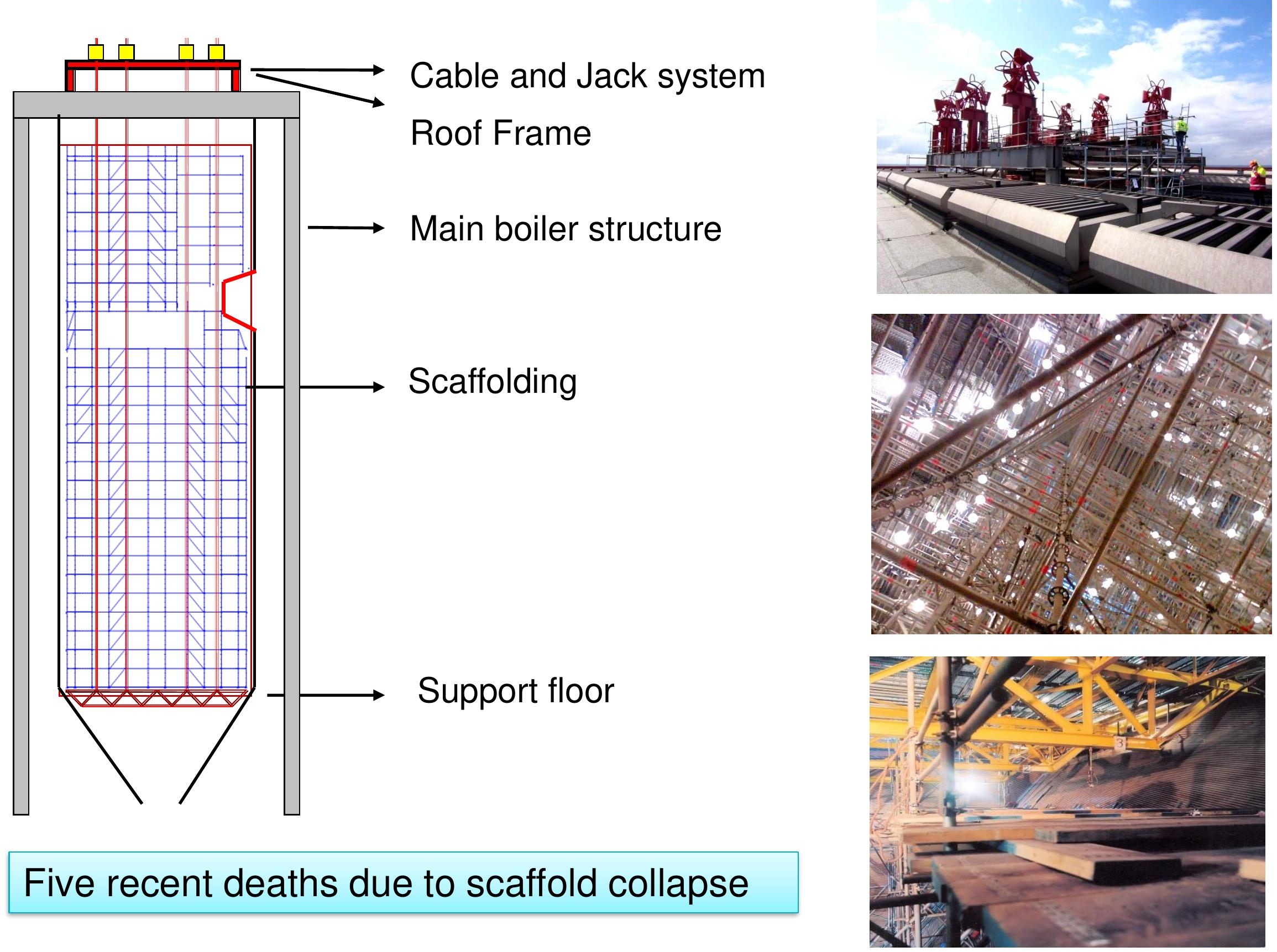




\section{Internal inspection of gas boiler using suspended platforms}

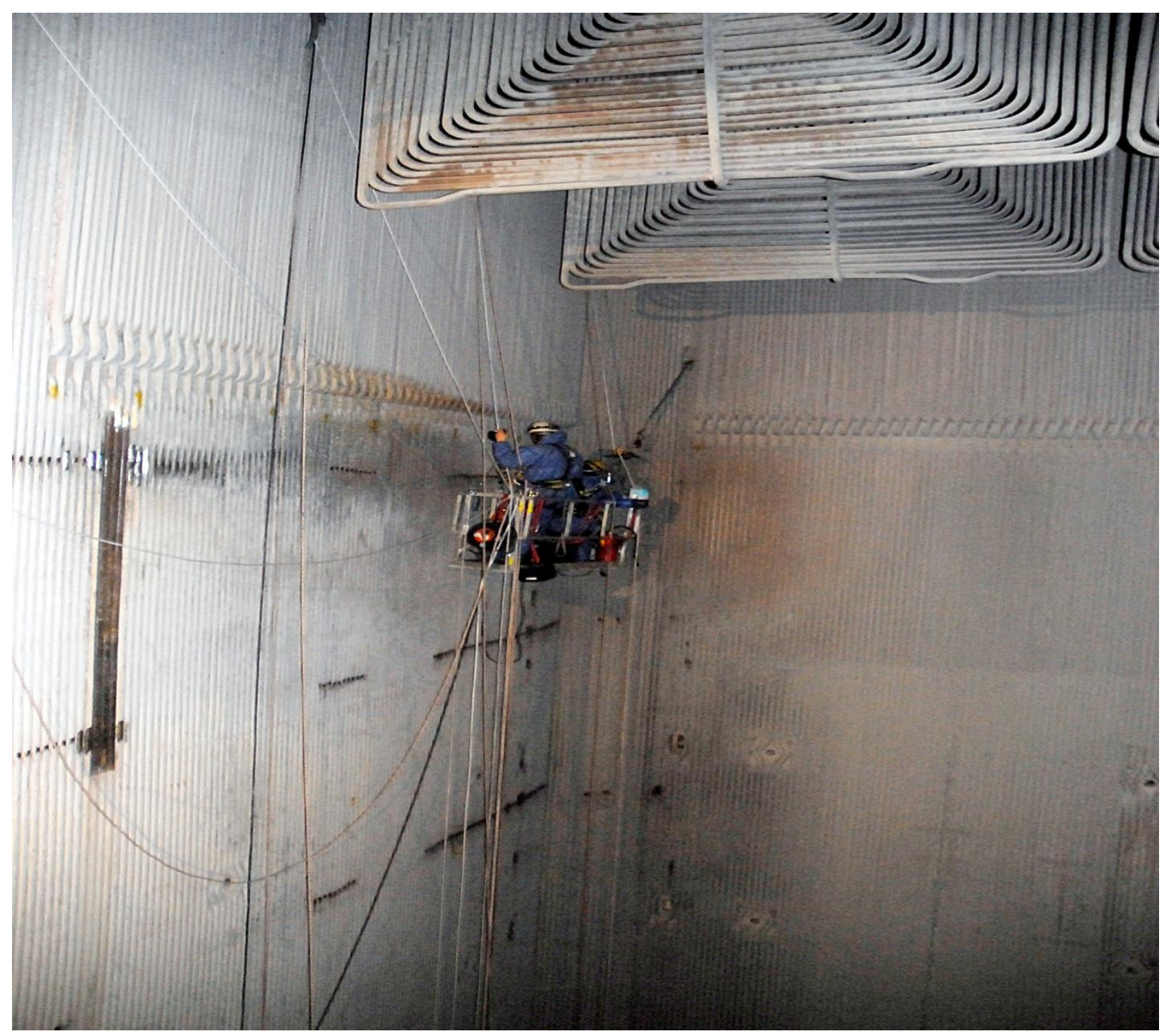




\section{Outage in Coal Power Plants}

\begin{tabular}{l|l|}
\hline $\begin{array}{l}\text { MAJOR OUTAGE } \\
\text { Every 8 -10 years }\end{array}$ & $\begin{array}{l}\mathbf{2 0 0} \text { MW unit, } 16 \\
\text { weeks }\end{array}$ \\
& $\begin{array}{l}110 \mathrm{MW} \text { unit, } 12 \\
\text { weeks }\end{array}$ \\
\hline OUTAGE & $200 \mathrm{MW}$ unit, 3 \\
Every second year & weeks \\
& $\begin{array}{l}110 \mathrm{MW} \text { unit, } 2-3 \\
\text { weeks }\end{array}$ \\
\end{tabular}

Opportunity to reduce turn-around time with robotics and automation 


\section{Robotic Non Destructive Testing (NDT)}

Ultrasound NDT of horizontal and vertical welds on a new build cargo container ship Odense Shipyard

Dimensions:

$30 \mathrm{~m}$ height

$30 \mathrm{~m}$ width 300m length

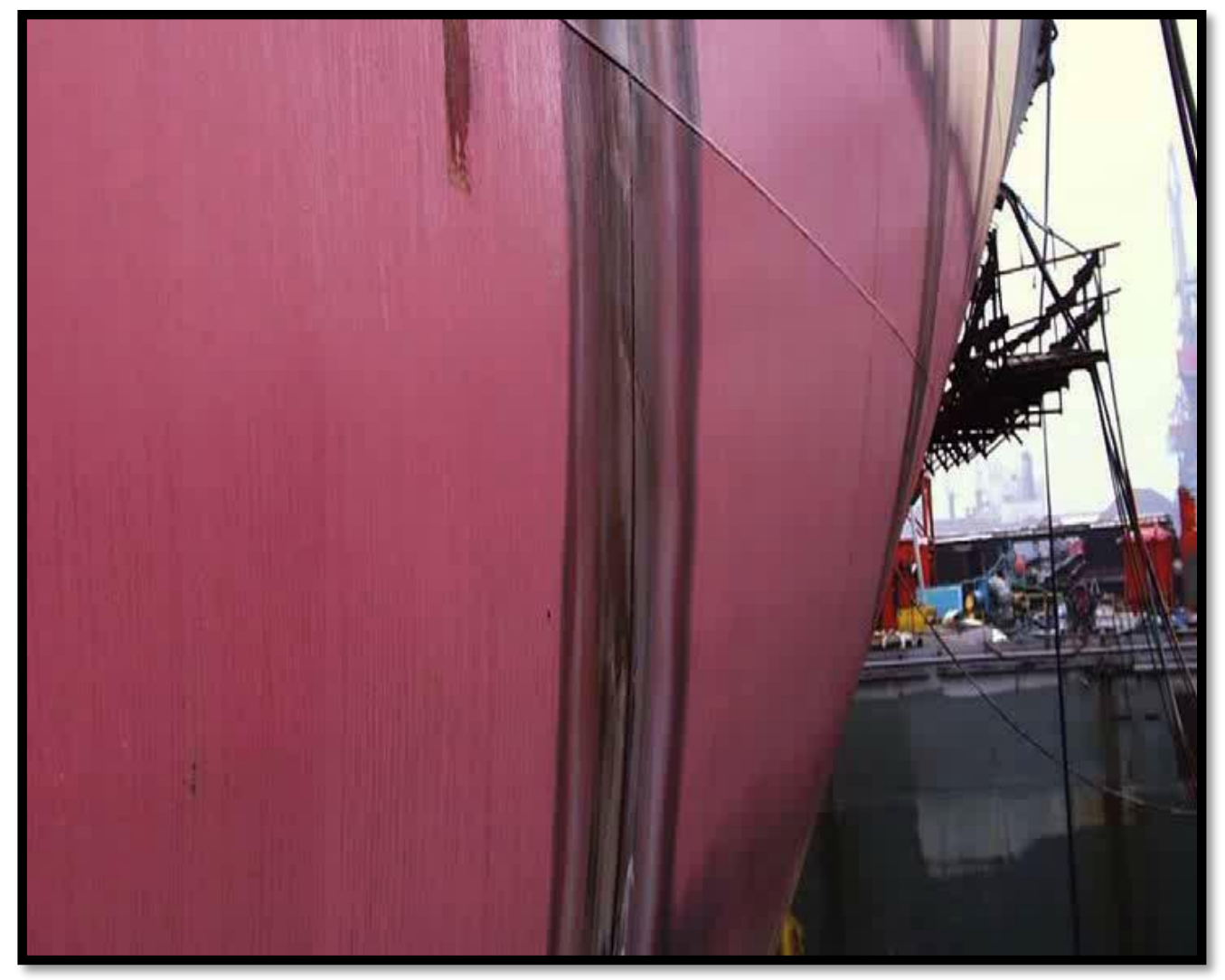




\section{The floating platform, mooring chain, oil \& gas flexible riser, flow-line, tie-back and tidal generator environment}

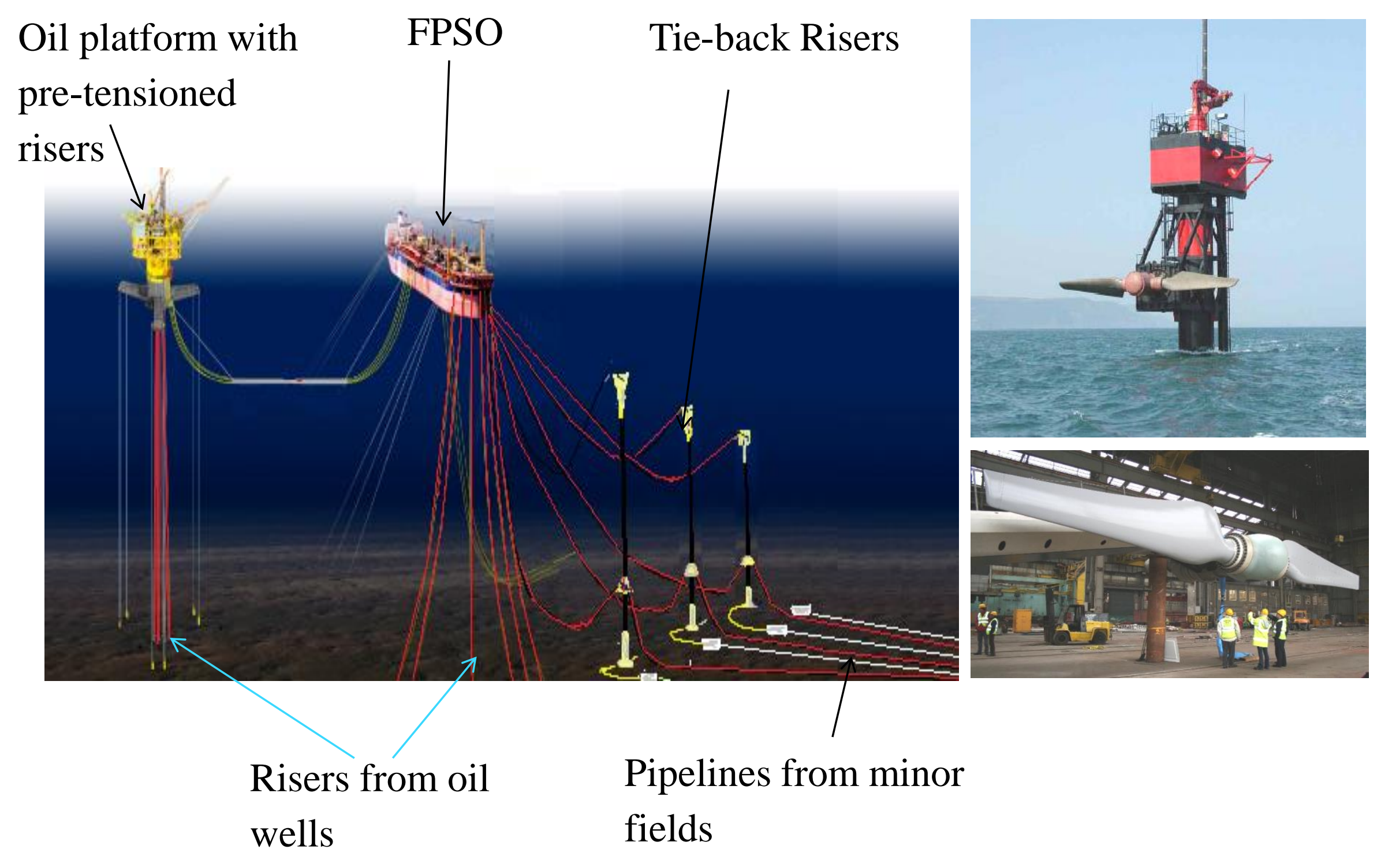




\section{Robotic Non Destructive Testing (NDT)}

R\&D of Mobile robots to provide access and perform NDT of

- $\quad$ very large structures

- test sites located in dangerous and hazardous environments

The aim is to

- $\quad$ reduce inspection costs, outage times during planned outages

- Provide in-service inspection where possible to eliminate outages 


\begin{tabular}{|l|l|}
\hline \multicolumn{2}{|l|}{ The $\mathbf{4}$ M's of Robotic Non-Destructive Testing } \\
\hline $\begin{array}{l}\text { Provide access to a } \\
\text { test site with mobile } \\
\text { robots }\end{array}$ & MOBILITY \\
\hline Deploy NDT probes & MANIPULATION \\
\hline $\begin{array}{l}\text { Acquire data to detect } \\
\text { and size defects }\end{array}$ & MEASUREMENT \\
\hline $\begin{array}{l}\text { Store and use data to } \\
\text { monitor state of } \\
\text { infrastructure }\end{array}$ & MONITORING \\
\hline
\end{tabular}




\section{Mobility \\ Manipulation}

Provide access to remote test site located in extreme environments 
Wall climbing robots that use pneumatic suction cups

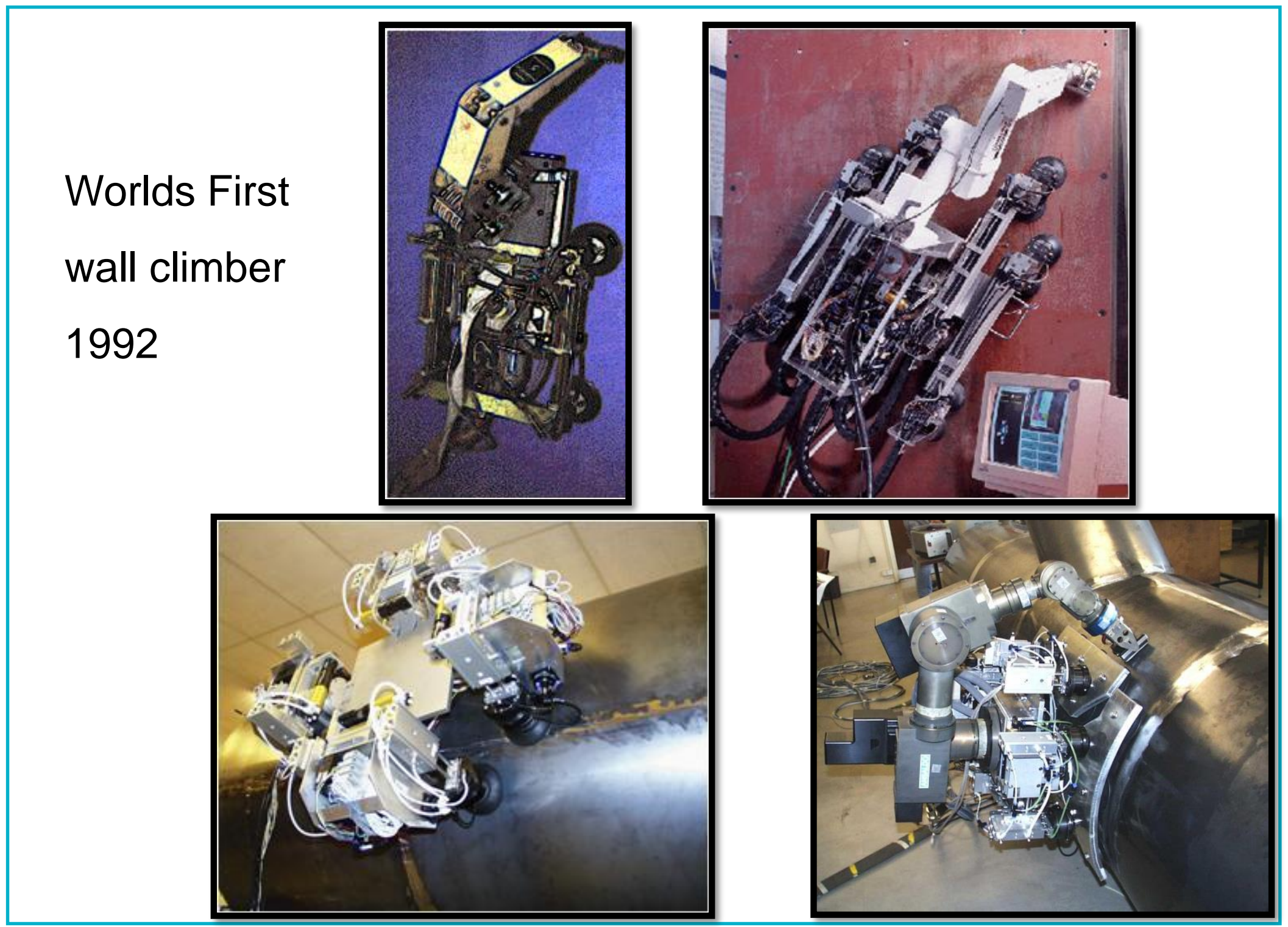




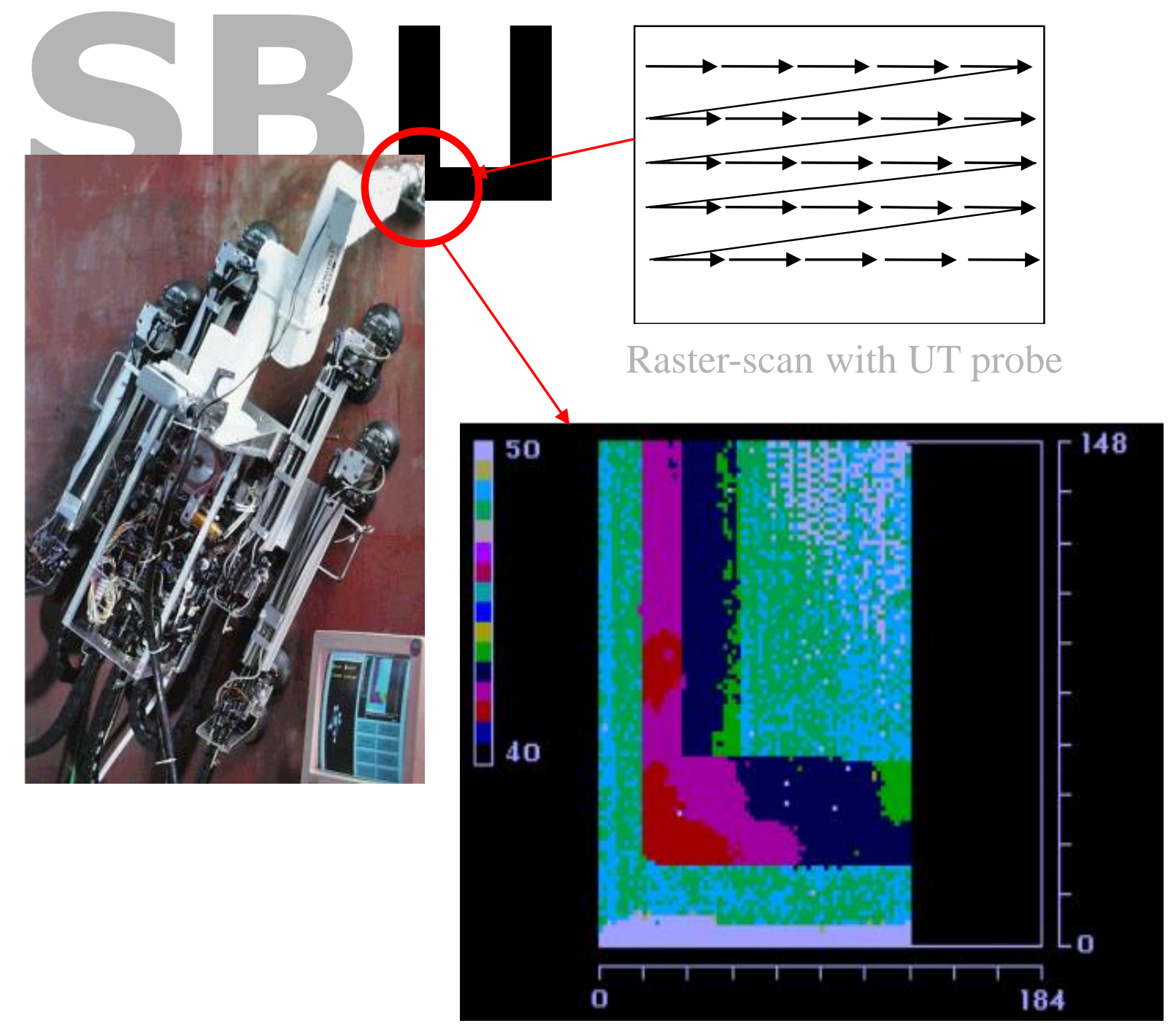

C-scan image of corrosion thinning (variable thickness 0 - $6 \mathrm{~mm}$ measured from the back wall) of a $10 \mathrm{~mm}$ thick steel plate, adjacent colors corresponding to thickness steps of $0.375 \mathrm{~mm}$. Data obtained with $5 \mathrm{MHz}$ wet contact compression wave probe ( $8 \mathrm{~mm}$ diameter) 

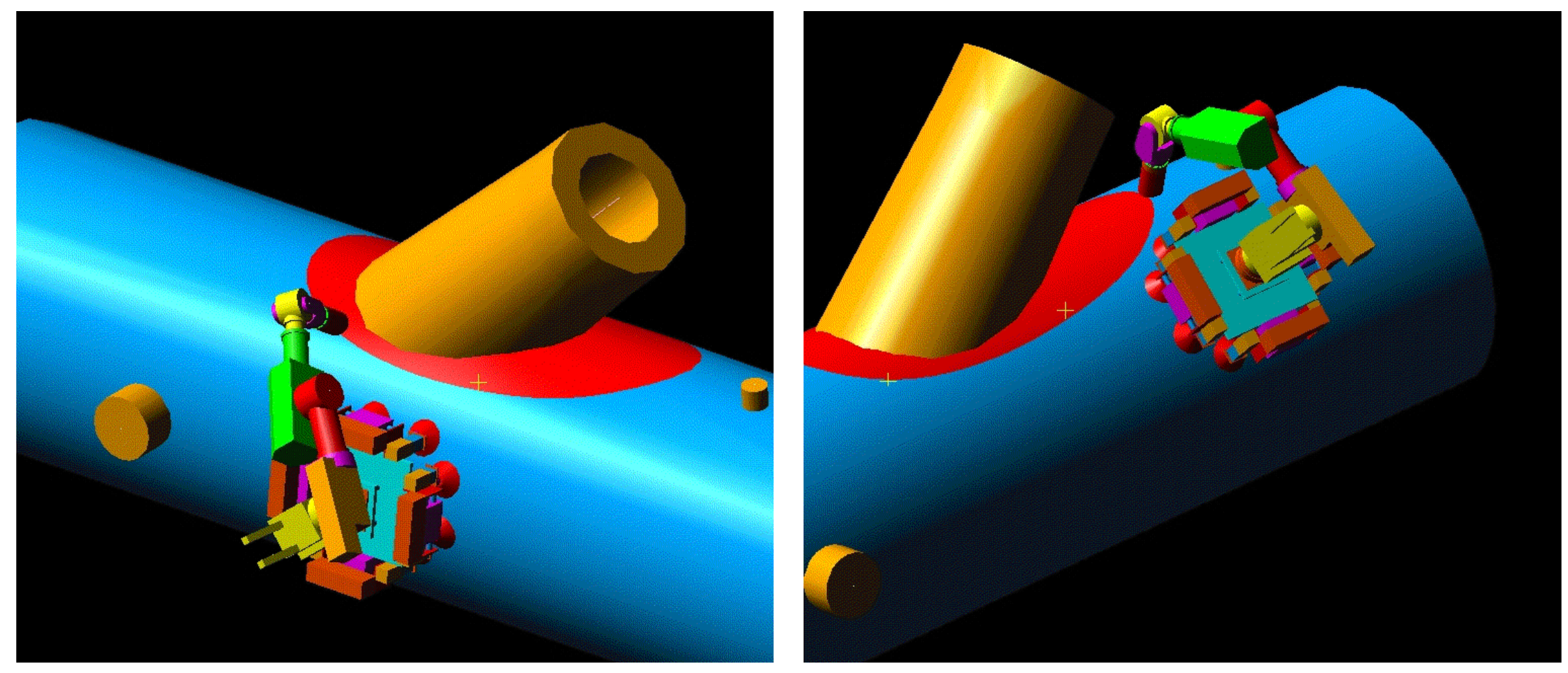

CAD schematic drawing - mobile inspection robot deploying NDT sensors with 7-axis arm. 


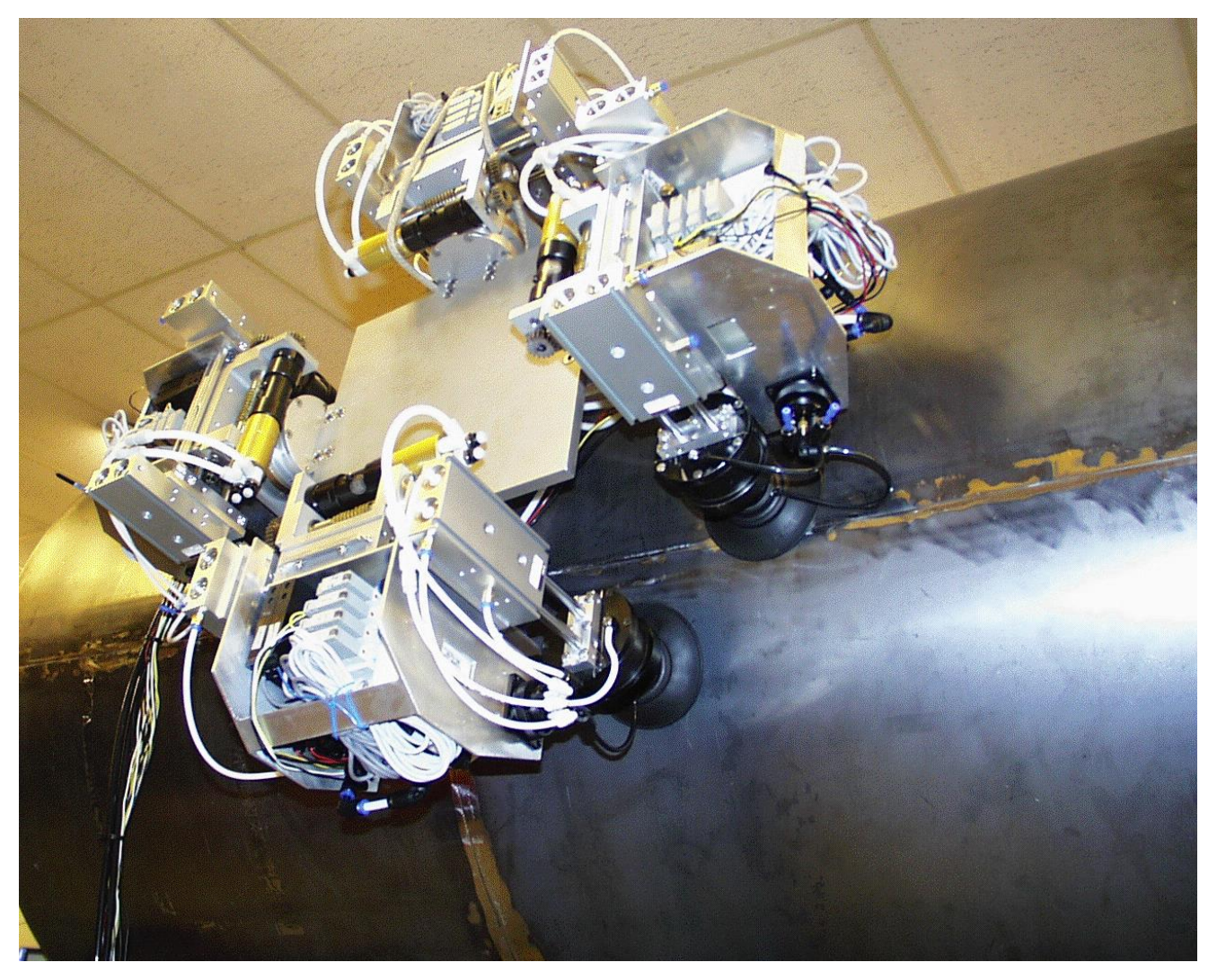

Prototype generic vehicle - 4 thigh joints for motion on spheres -conventional suction cups -payload $6 \mathrm{~kg}$ with a safety factor of 3 
Ultrasound NDT of nozzle welds in primary circuit of nuclear power plant

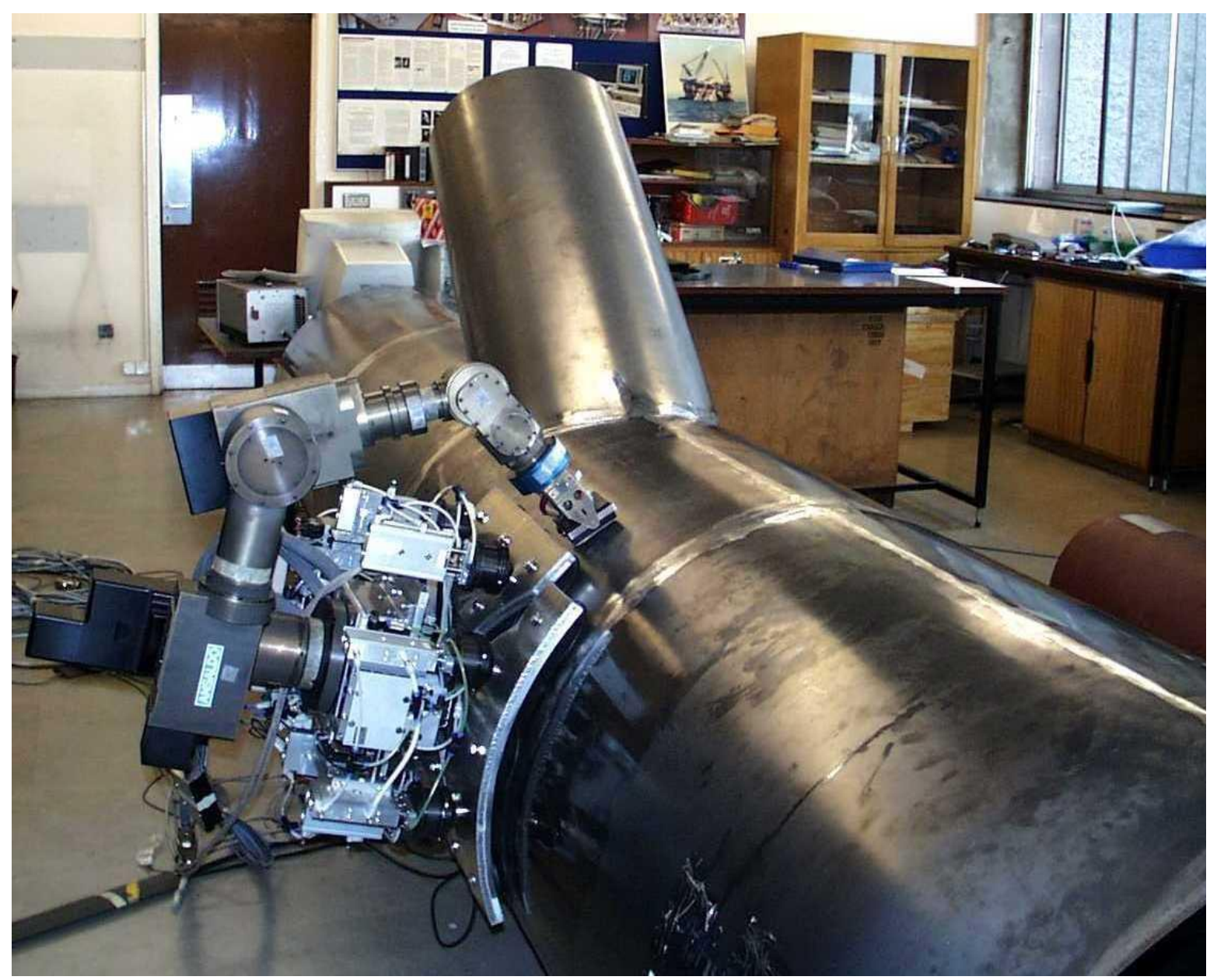

Pipe diameter $860 \mathrm{~mm}$, vehicle mass $=30 \mathrm{~kg}, 500 \times 500 \mathrm{~mm}$, $\max P=37$ $\mathrm{kg}$, arm mass $=22 \mathrm{~kg}, 7 \mathrm{DOF}$, arm payload $=5 \mathrm{~kg}$, repeatability \pm 1 $\mathrm{mm}$, couplant retrieval system, force controller 


\section{Climbing NDT robots that use different adhesion techniques: permanent magnets, pneumatic suction cups and Vortex machines}
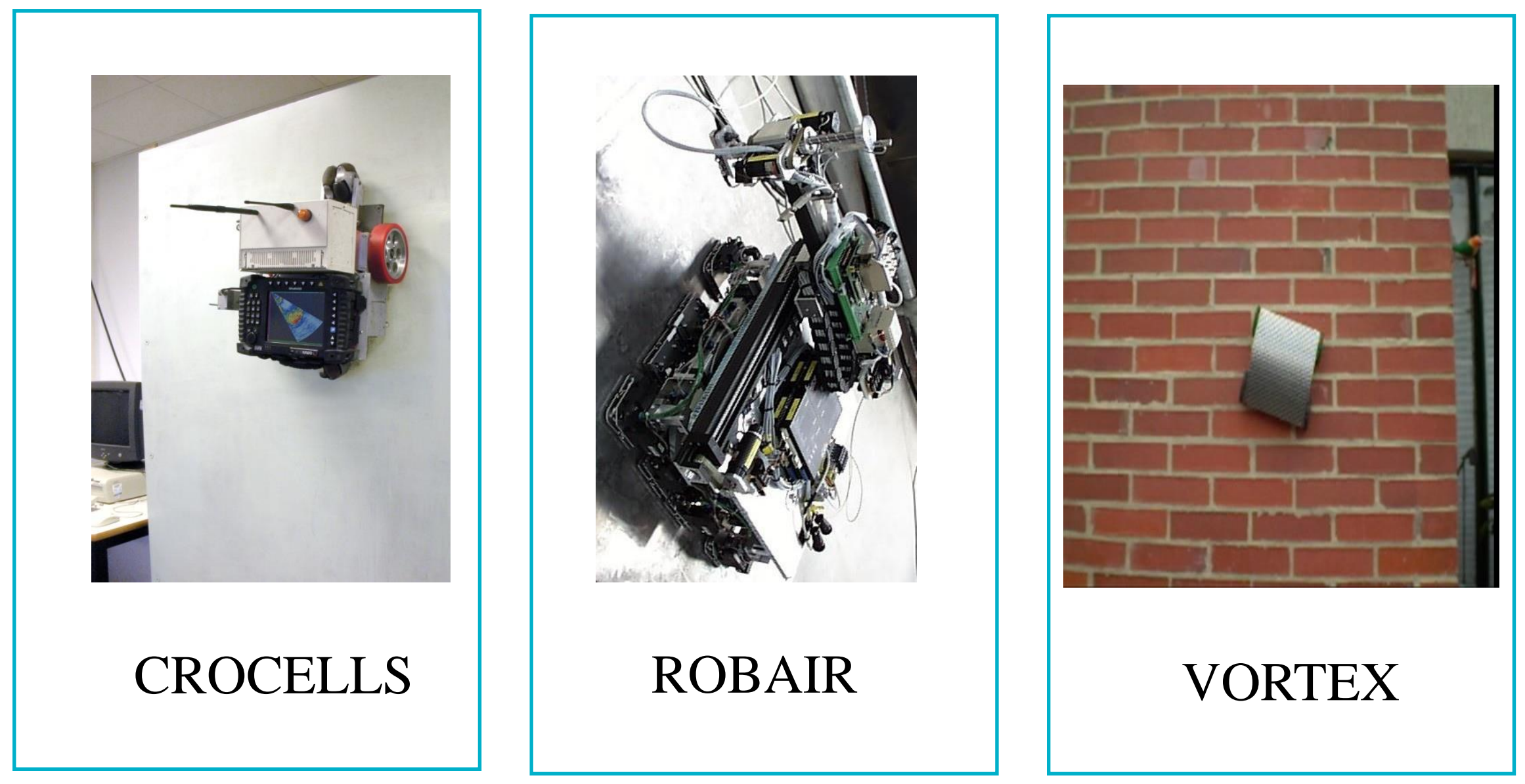
Wall climbing robots for the NDTof welds on cargo containers ships

Permanent magnets

Wireless control and data

acquisition

Ultrasonic phased array NDT

Laser weld profiling and tracking

Mass $35 \mathrm{Kg}$
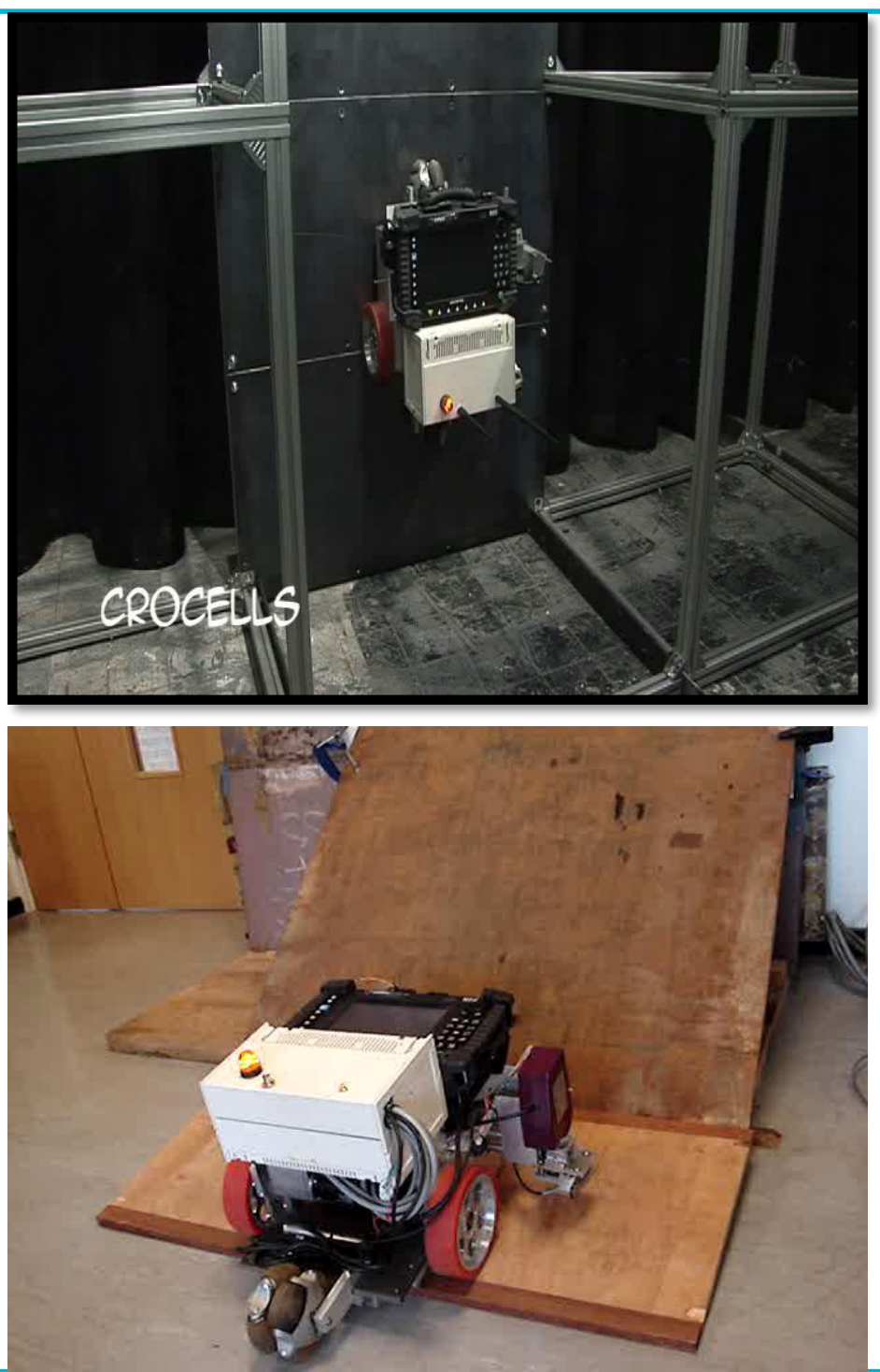

InnovateUK funded project AWI (Autonomous Weld Inspector) is currently developing a more advanced version of this robot 


\section{Climbing Robot Cell for welding and NDT - CROCELLS}

- Team of climbing robots

- One performs Electric arc welding by profiling seam with a laser system

- A utility robot follows the welder and carries the wire drum and feeder

- A tug robot aides the welding robot

- An NDT robot tracks the welding hot spot and performs weld inspection with phased array ultrasonics

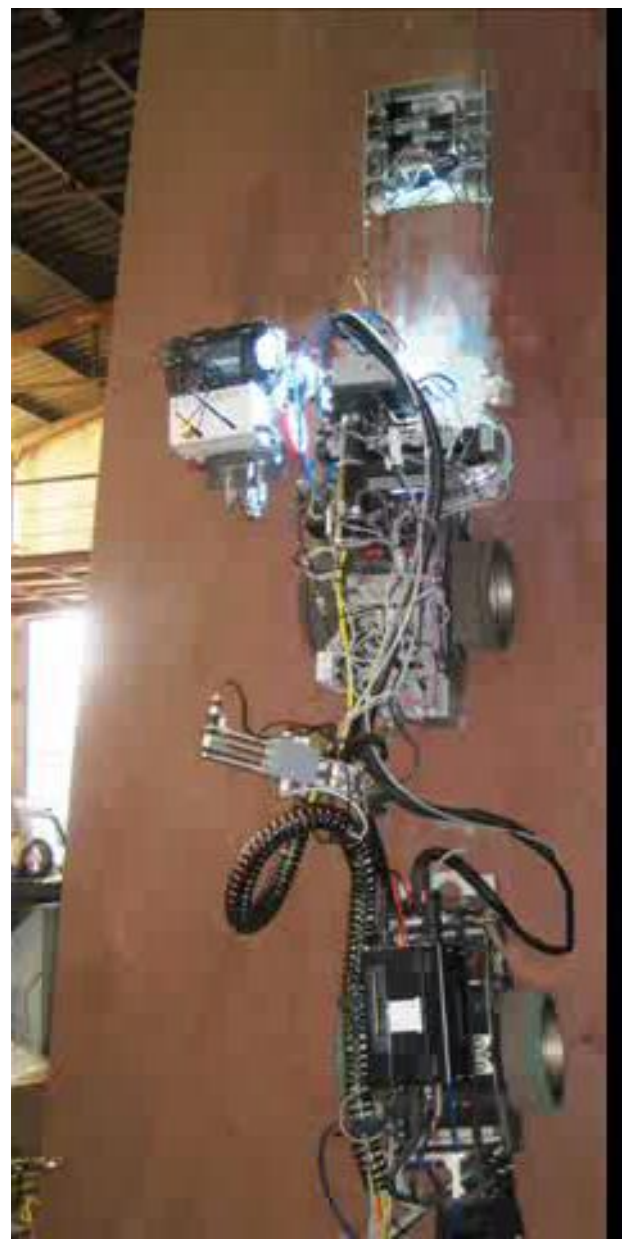


Magnetic adhesion climbing robots

Adapt to surface curvatures (concave or convex) or change surfaces

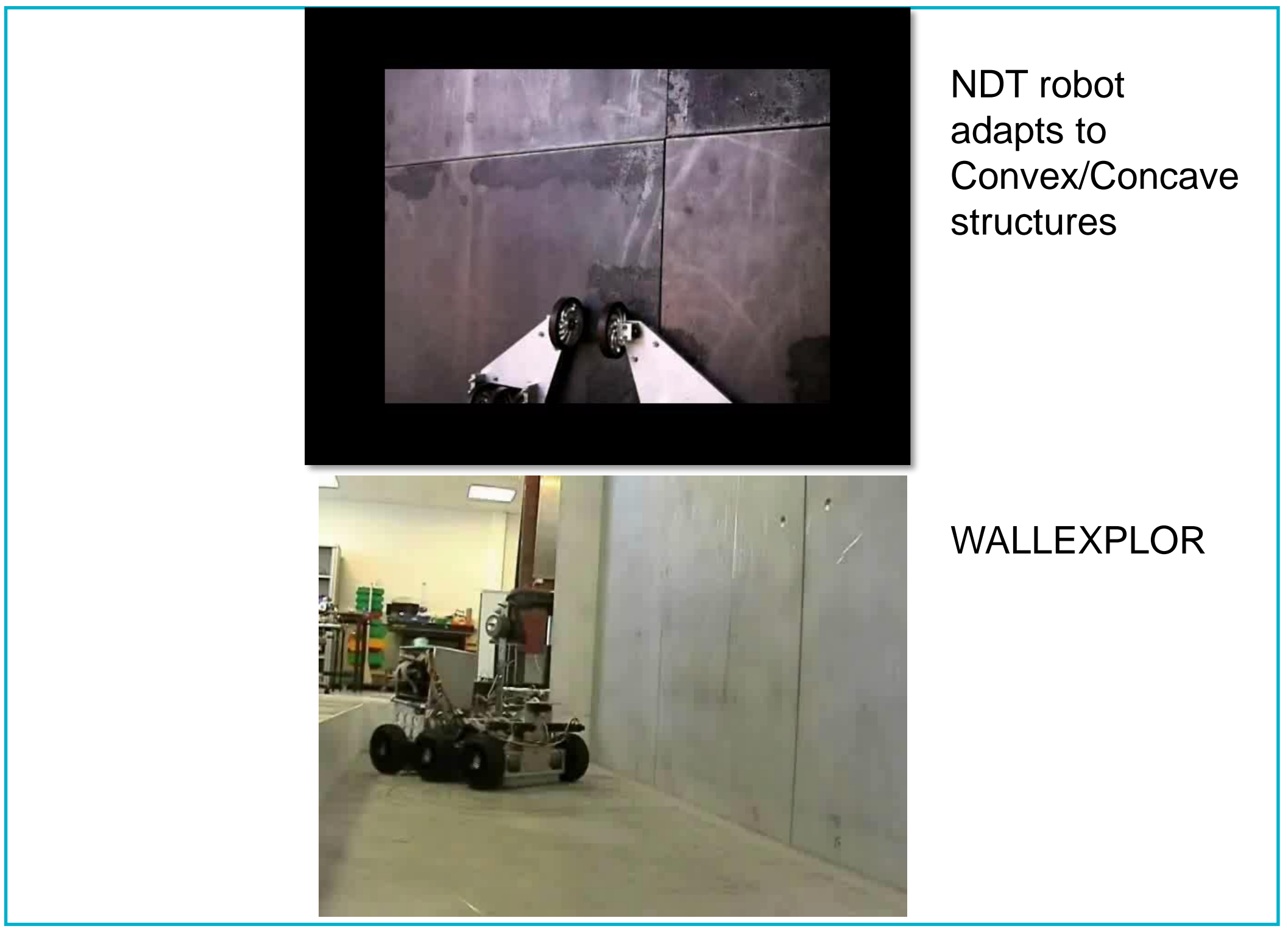




\section{Wall climbing robots for NDT, inspection and}

surveillance on non-ferrous surfaces

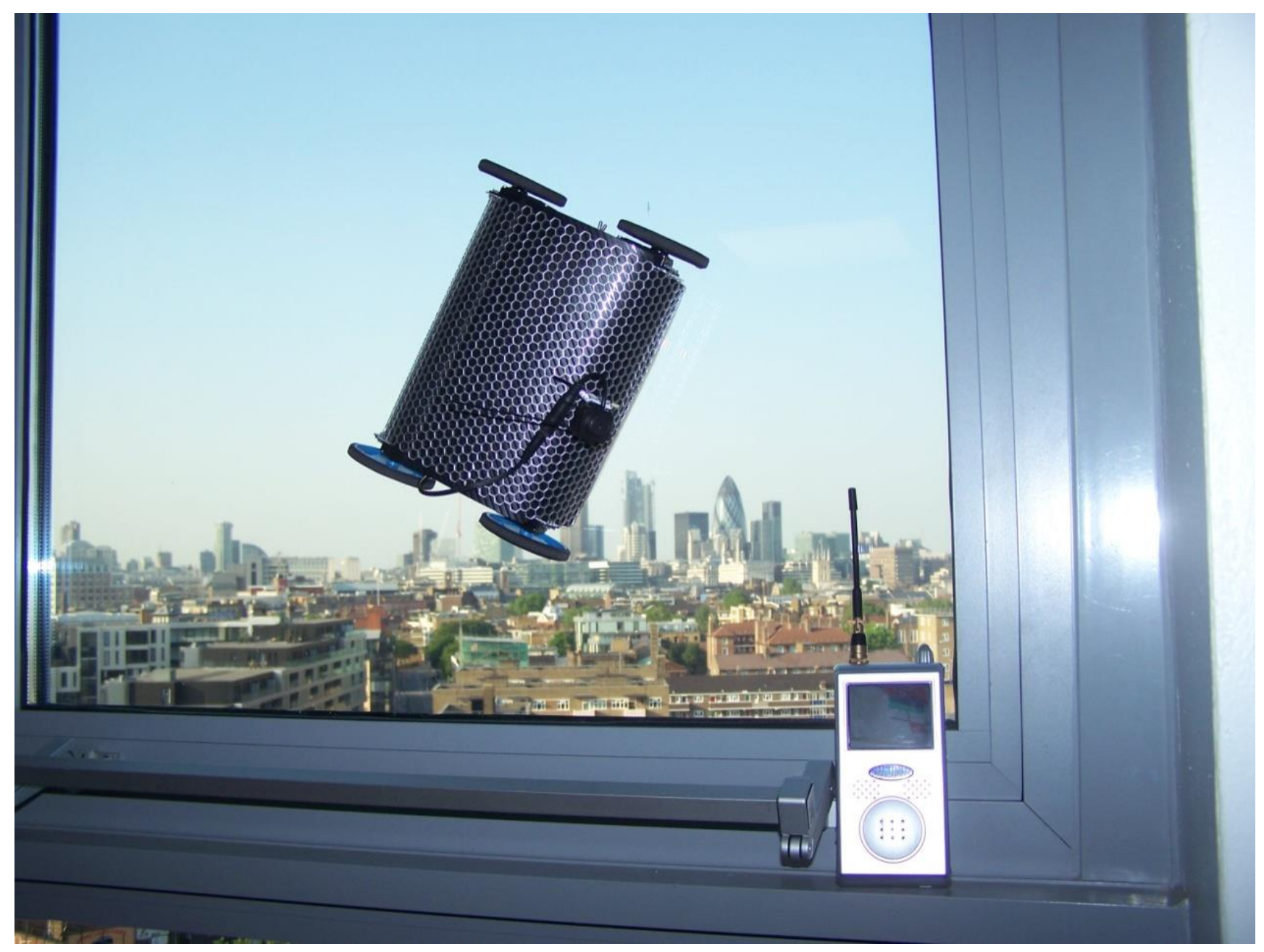


ANSYS

analysis of

streamlines and

pressures

created by VORTEX

machines

Aim: Increase

Payload

capability of

climbing robot

Achieved: $4 \mathrm{~kg}$

with an A4

sized robot.

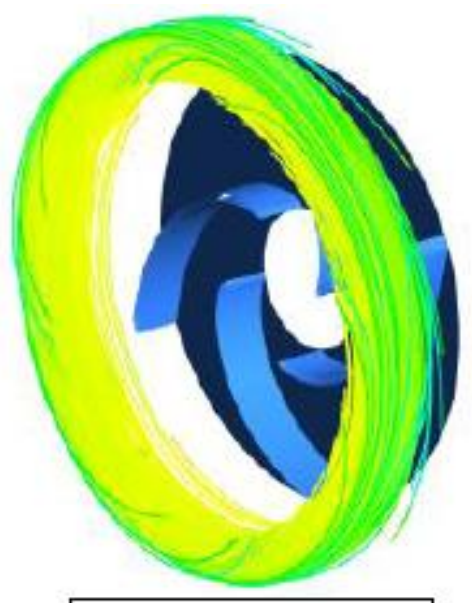

(A) Streamlines inside the fluid outer domain

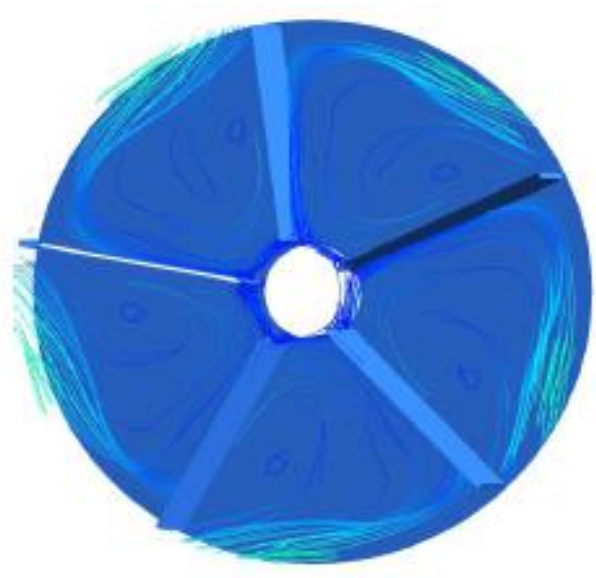

(B) Streamlines inside the blade domain

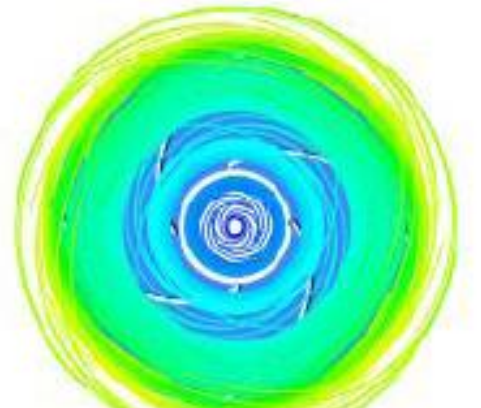

(C) Streamlines in the hub domain

(D) Streamlines in all the domains with fewer number of streamlines

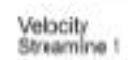

Stramine ! $1.075 \mathrm{e}+002$
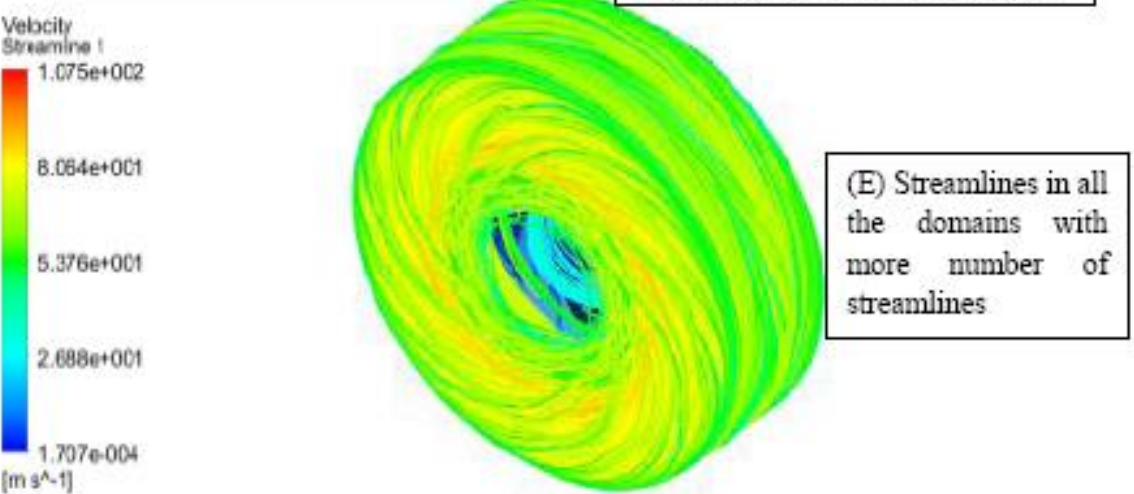

Figure 3-10 isometric view to show the streamlines inside the vortex chamber in the blades 
VORTEX MACHINES: Wall climbing robots for NDT, inspection and surveillance on non-ferrous surfaces

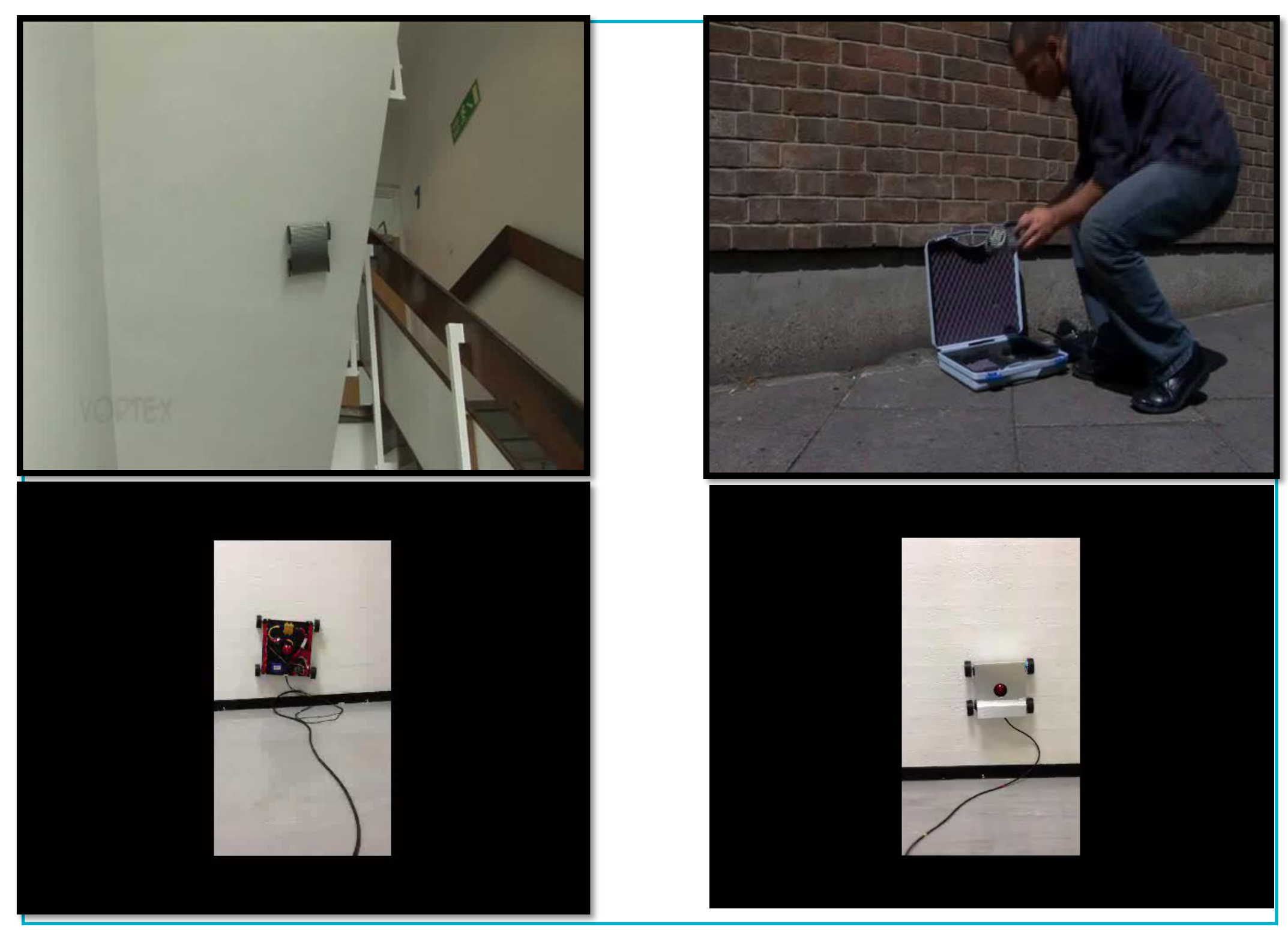




\section{Measurement}

Non-destructive testing (NDT)

techniques 


\section{$0^{\circ}$ compression wave}

Ultrasonic probe

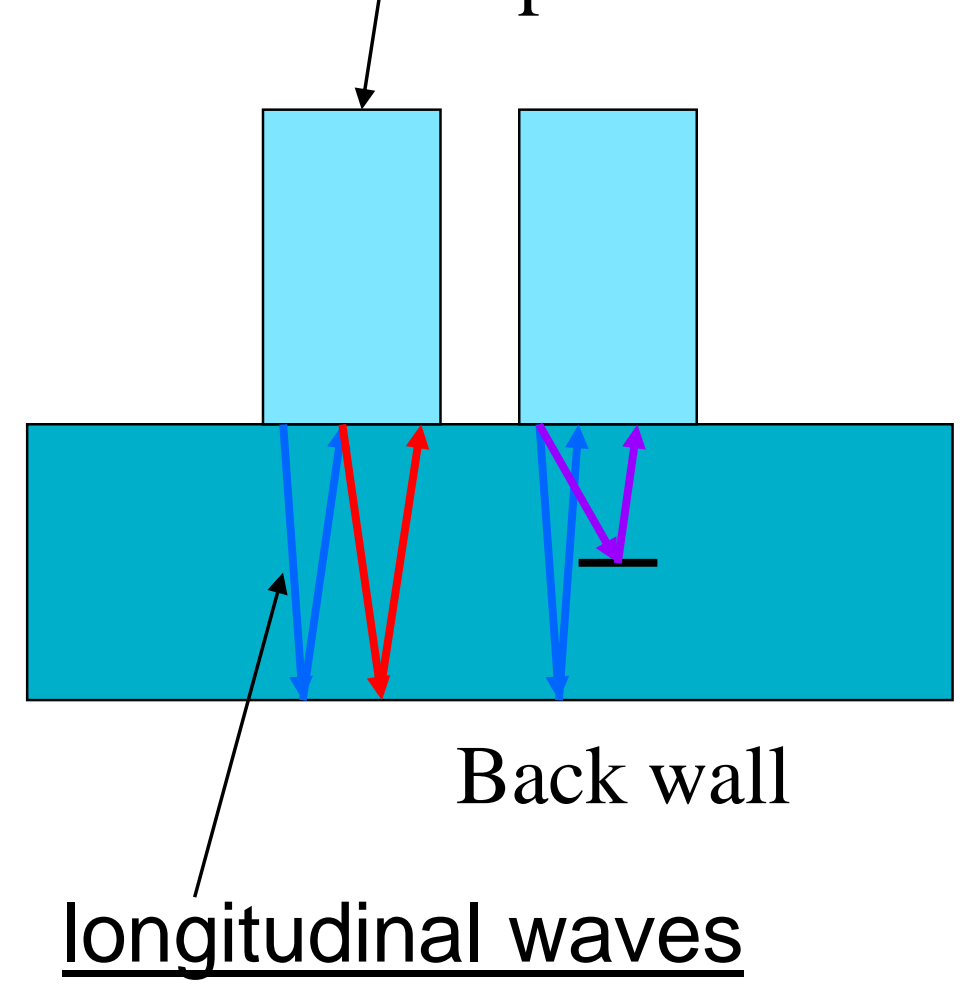

\section{A-Scan}

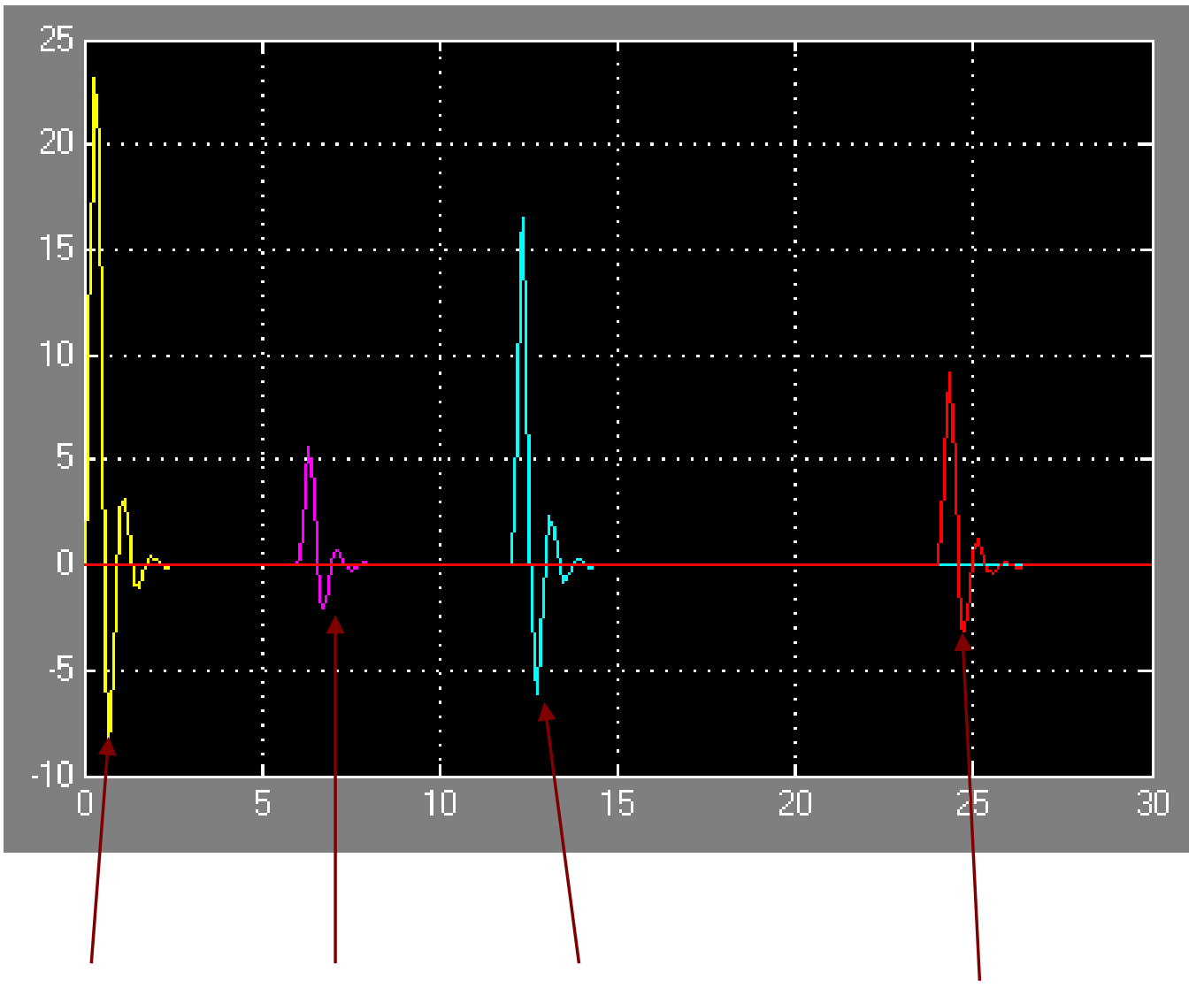

Transmitted Defect Back-

SecondBack ultrasonic echo wall echo

pulse 
Time Of Flight Diffegaction (TOFD) method B-Scan imaging

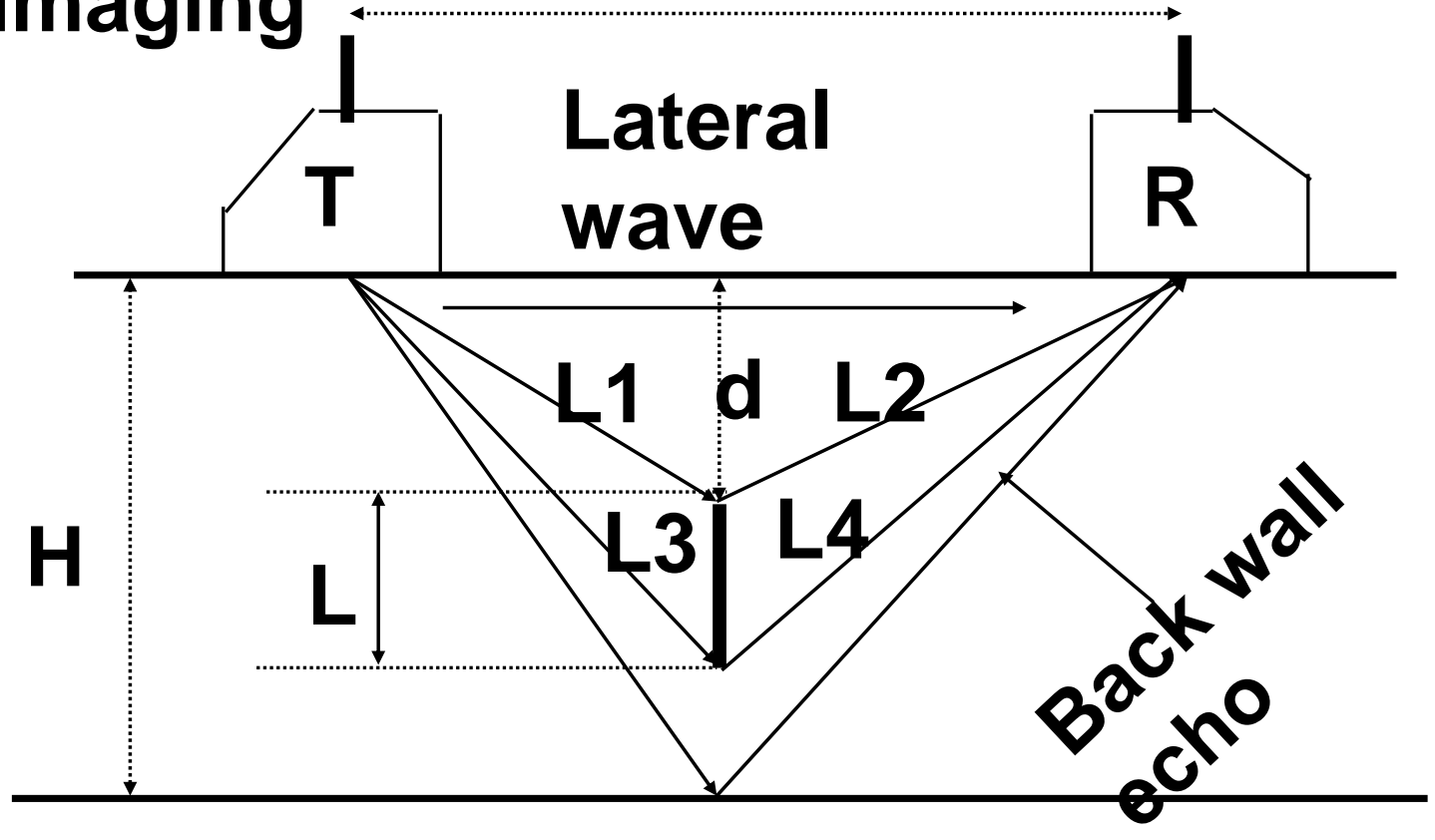

$\mathrm{T}$ - Transmitter

$\mathrm{R}$ - Reciever

$\mathrm{H}$ - Plate thickness

$L$ - Size of the defect

$t_{L}$ - Time for the lateral wave

$t_{1}$ - Time for the top tip diffraction along the path (L1+L2)

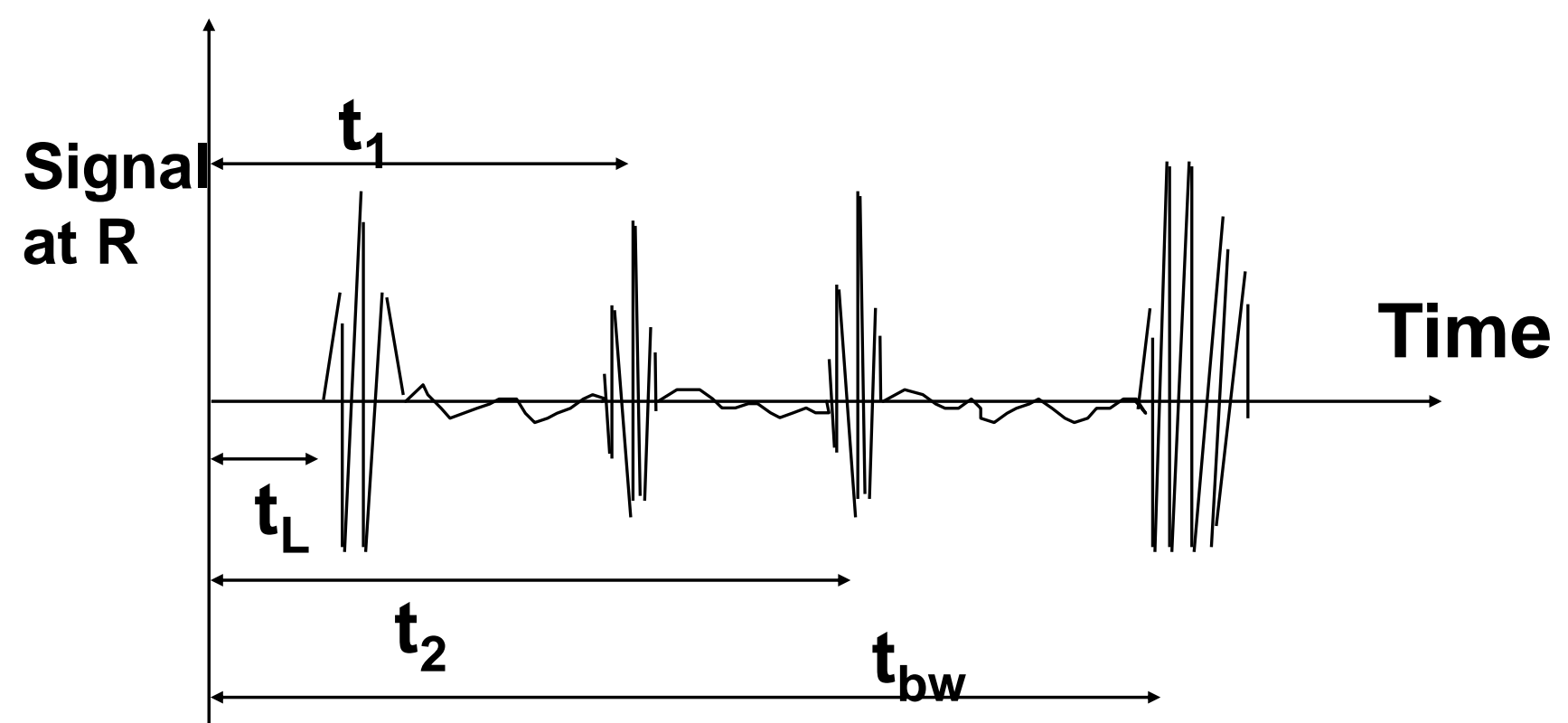

$t_{2}$ - Time for the bottom tip diffraction along the path (L3+L4)

$t_{b w}$ - Time for the back wall echo 


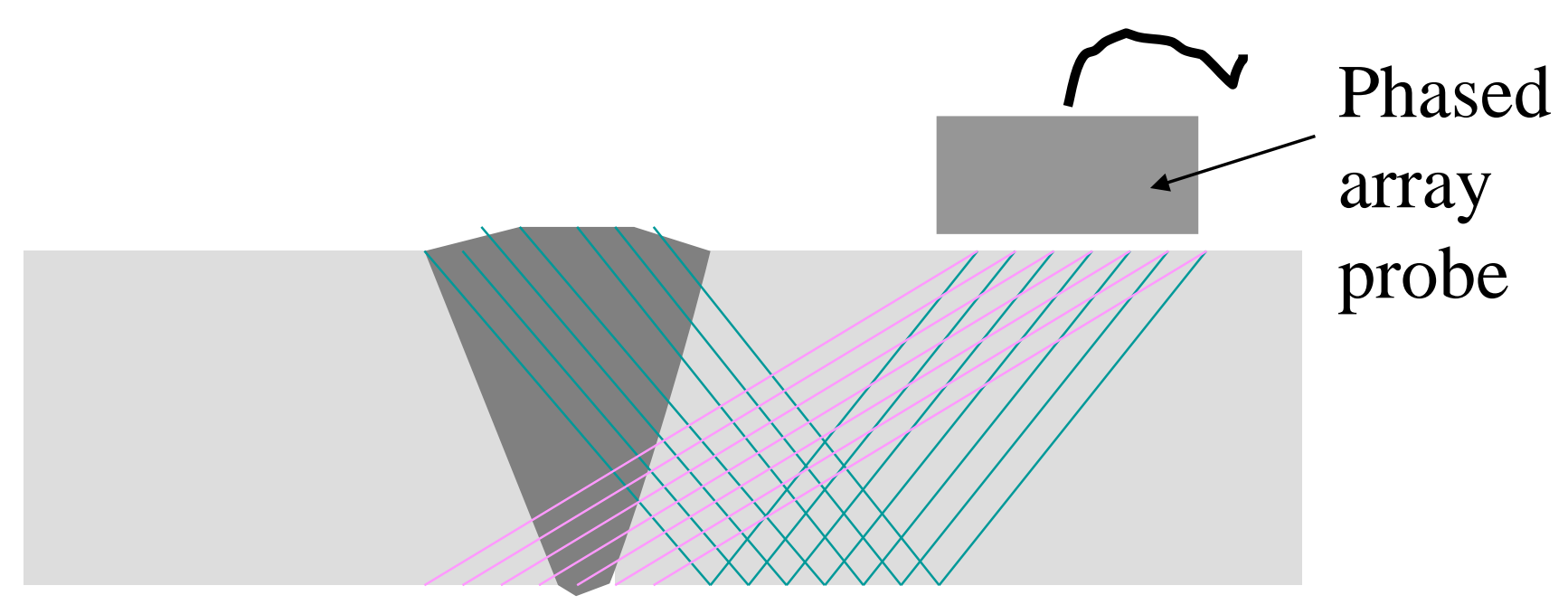

- Array of elements, all individually wired, pulsed and time shifted.

- Each element generates a beam when pulsed; these beams constructively and destructively interfere to form a wavefront.

- Electronic beam steering reduces the number of scanning axes required to examine a defect 


\section{EDDY-CURRENT INSPECTION}

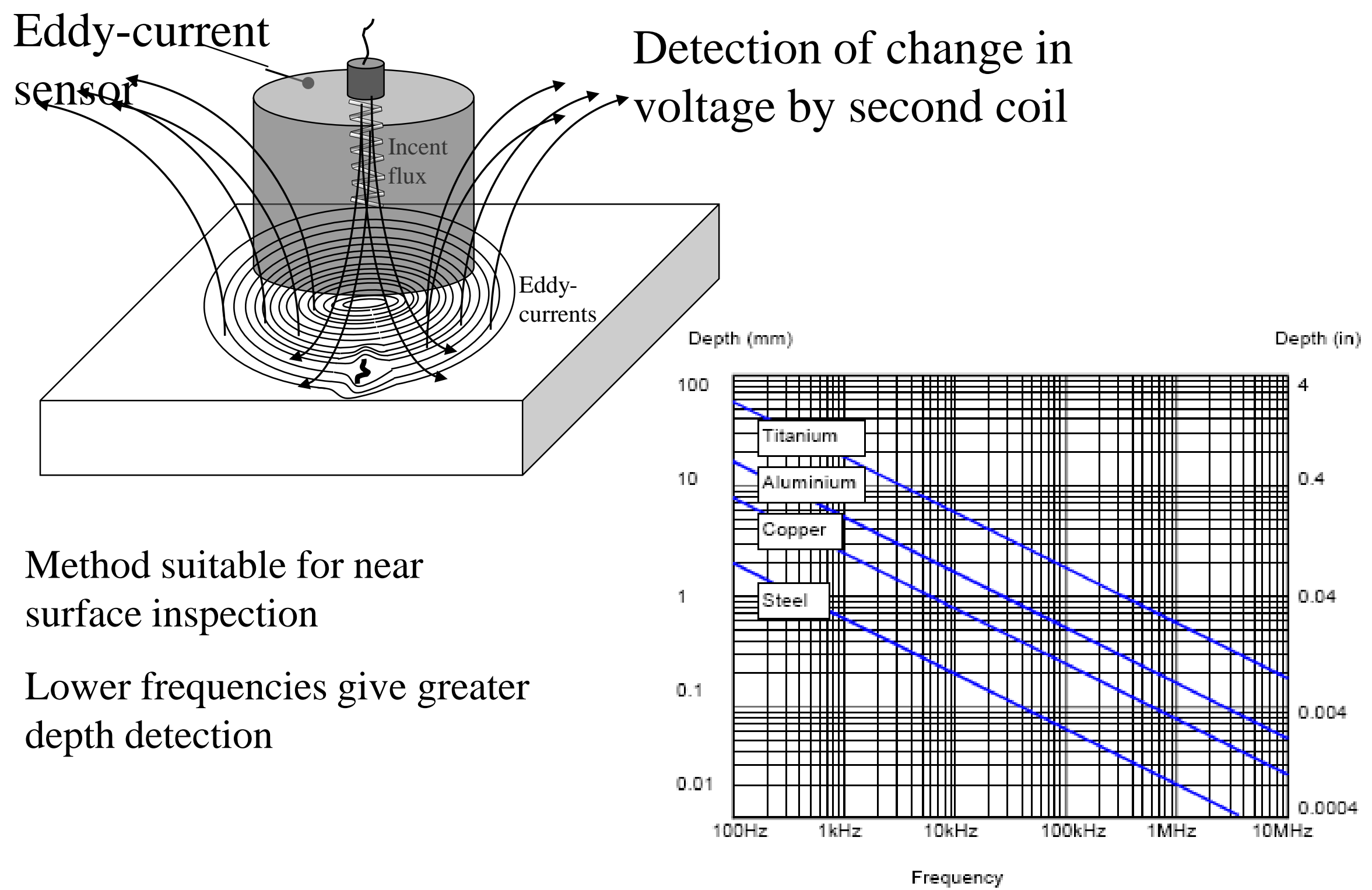




\section{Thermographic NDT}
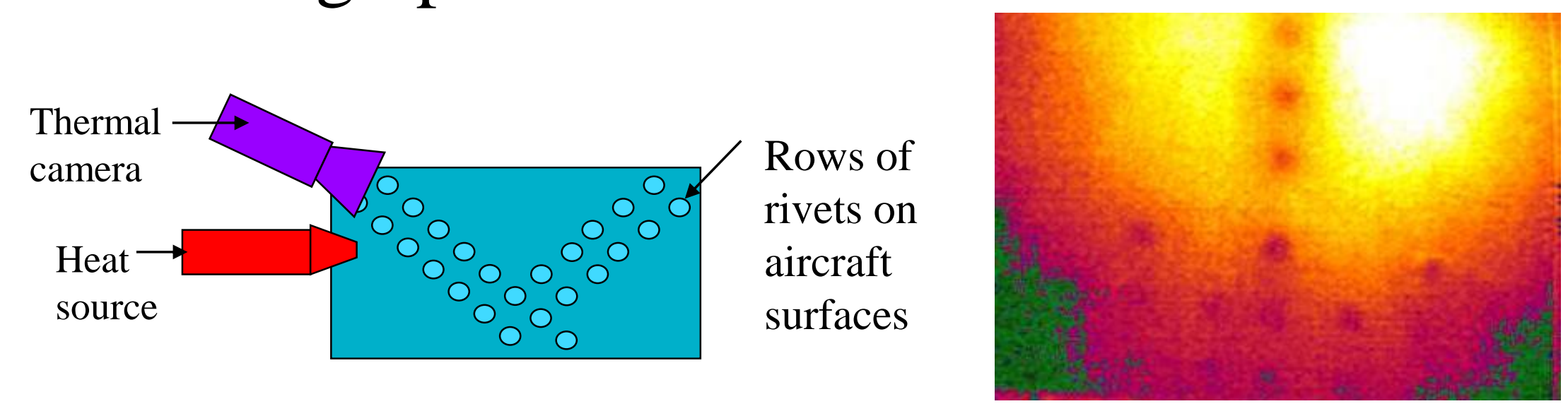

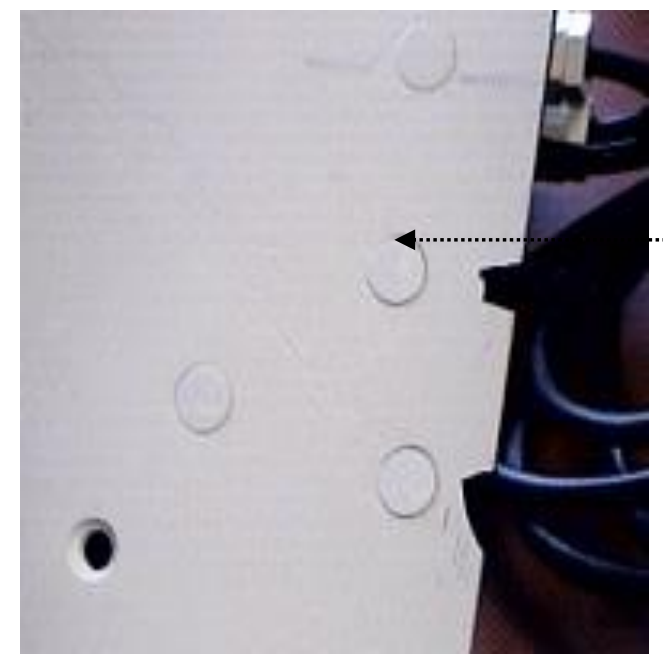

Loose rivet on an aircraft wing

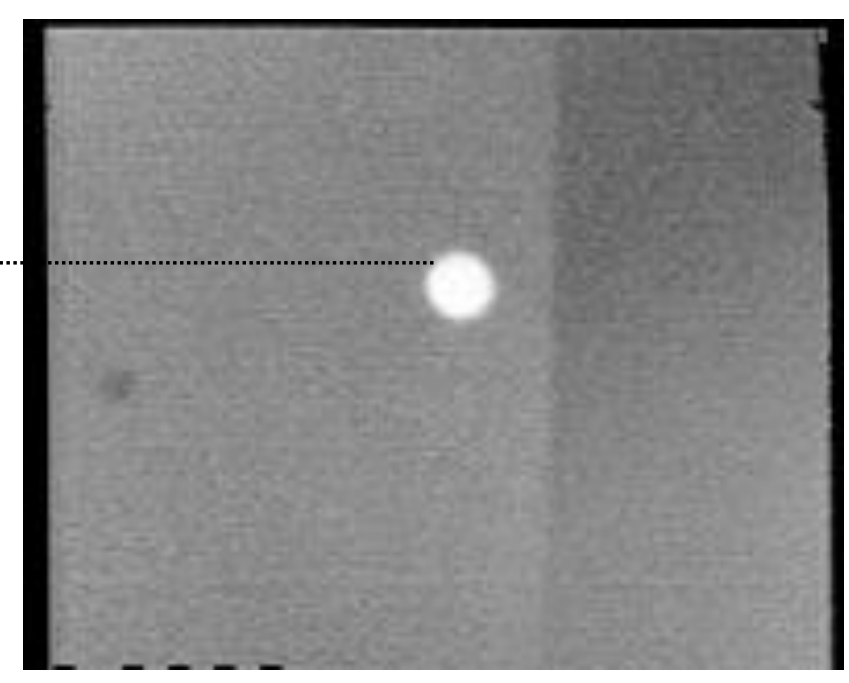

Thermal image of loose rivet 


\section{Examples: imaging of rivet defects with Ultrasound Phased Arrays, Eddy Currents}

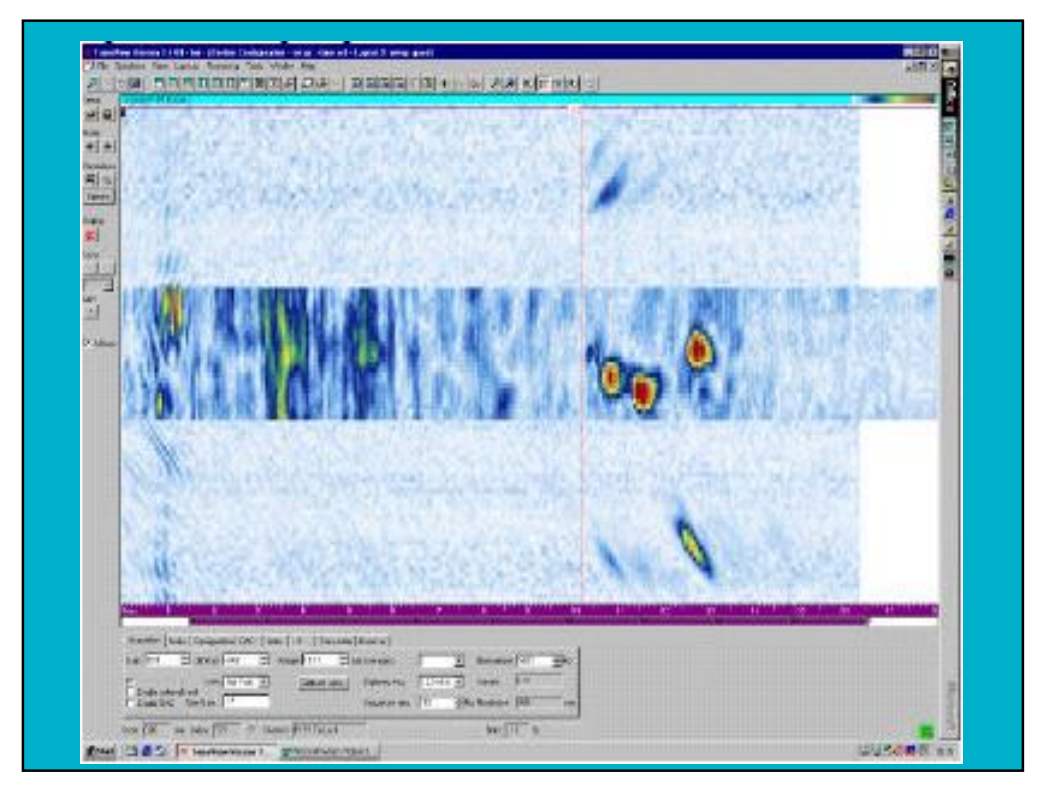

ULTRASONIC PHASED ARRAY to inspect rivets on aircraft, ROBAIR project

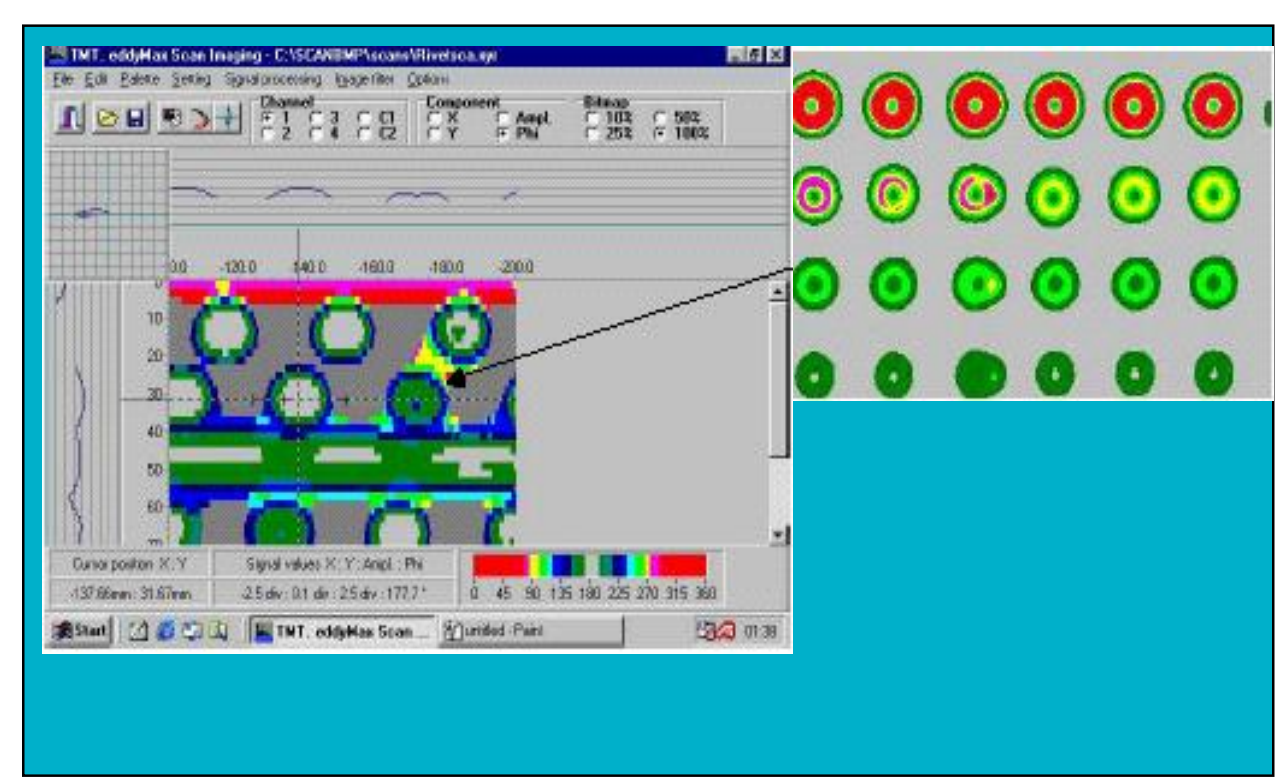

EDDY CURRENT inspection of rows of rivets on the wings and fuselage of aircraft, ROBAIR project - detects slot between two rivets 
$>$ Petrochemical storage tanks

$>$ Nuclear pressure vessels and pipes

$>$ Nuclear decommissioning -radiation cells, aerial stacks, buildings

$>$ Off-shore structures - Mooring chains, oil and gas flexible risers, FPSO's

NDT ROBOT PROTOTYPES FOR INDUSTRIAL INSPECTION TASKS 


\section{STORAGE TANK INSPECTION}

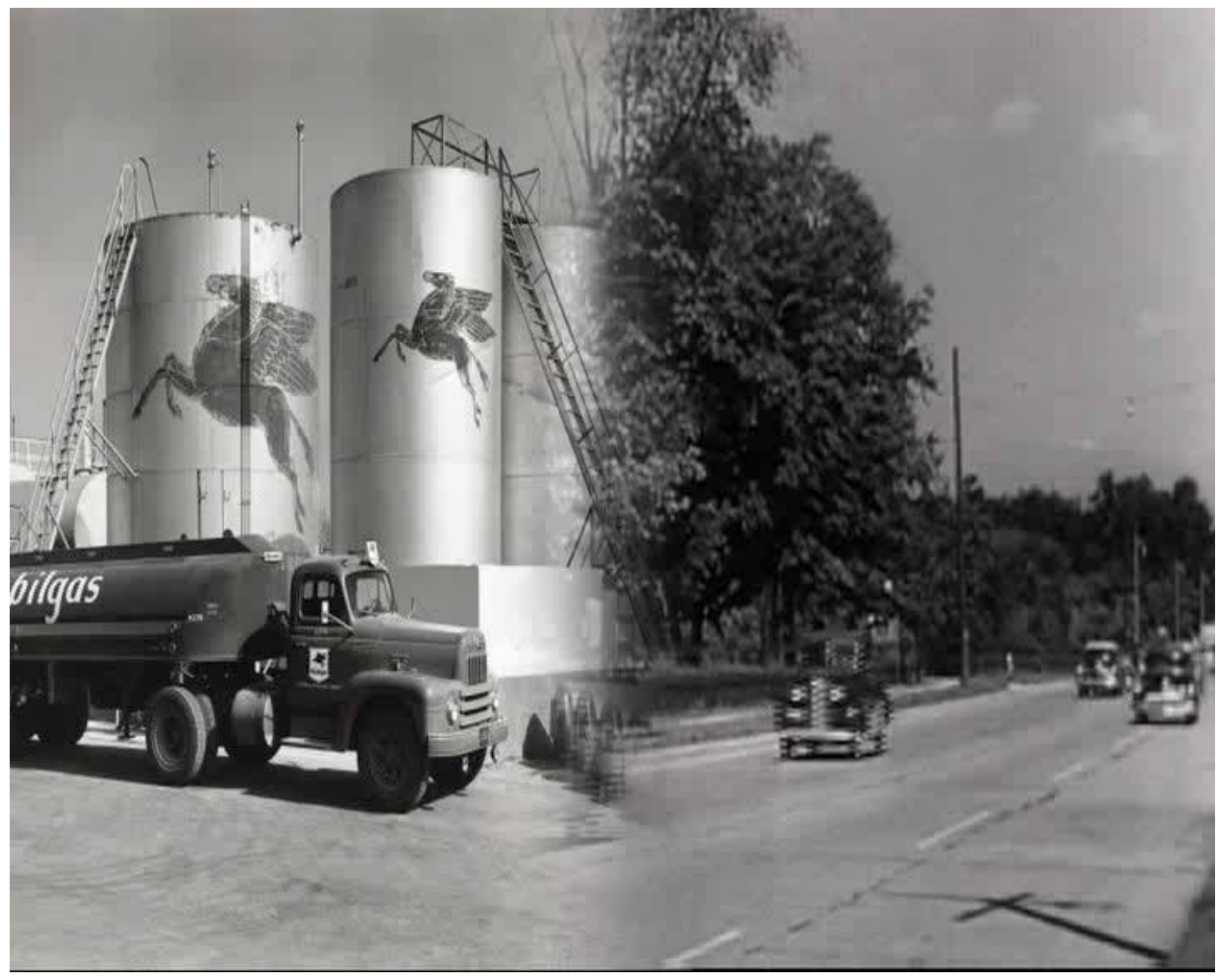




\section{In-service inspection of petro-chemical storage tanks with mobile robots - RobTank project}

Worldwide, over 218,000 petrochemical storage tanks and 53,000 large storage tanks with diameter $>50 \mathrm{~m}$ are mostly inspected with outages. A large $100 \mathrm{~m}$ diameter crude oil tank can be out of service for up to 9 months

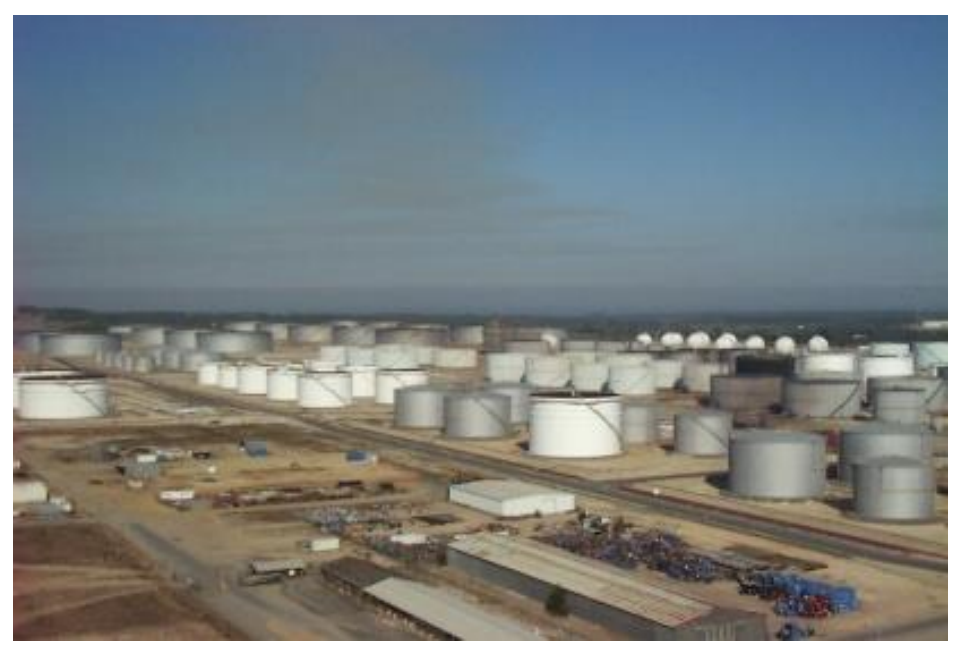

Existing tank floor inspection activities Preparing recipient tank Moving contents to the recipient tank Opening the tank under inspection De-gassing the tank Cleaning the tank - Sludge removal Manual Inspection conducted by personnel Closing the tank after inspection Refilling the tank Checking seals, vents, hoses etc.

Average Total Cost $€ 90000$

$80 \%$ of cost is opening and closing the tank 
CLEAN TANKS Diameter 2 to 20 metres, fixed roof. Visual inspection, a few ultrasonic thickness measurements.

Crude oil tanks floating roofs, dia 20 - 100 metres, carbon steel. Floor thickness of 6$12.5 \mathrm{~mm}$, Preparation: 6-9 months .Another 36 months to clean .

Visual inspection followed by MFL. UT final method to validate the problem areas.
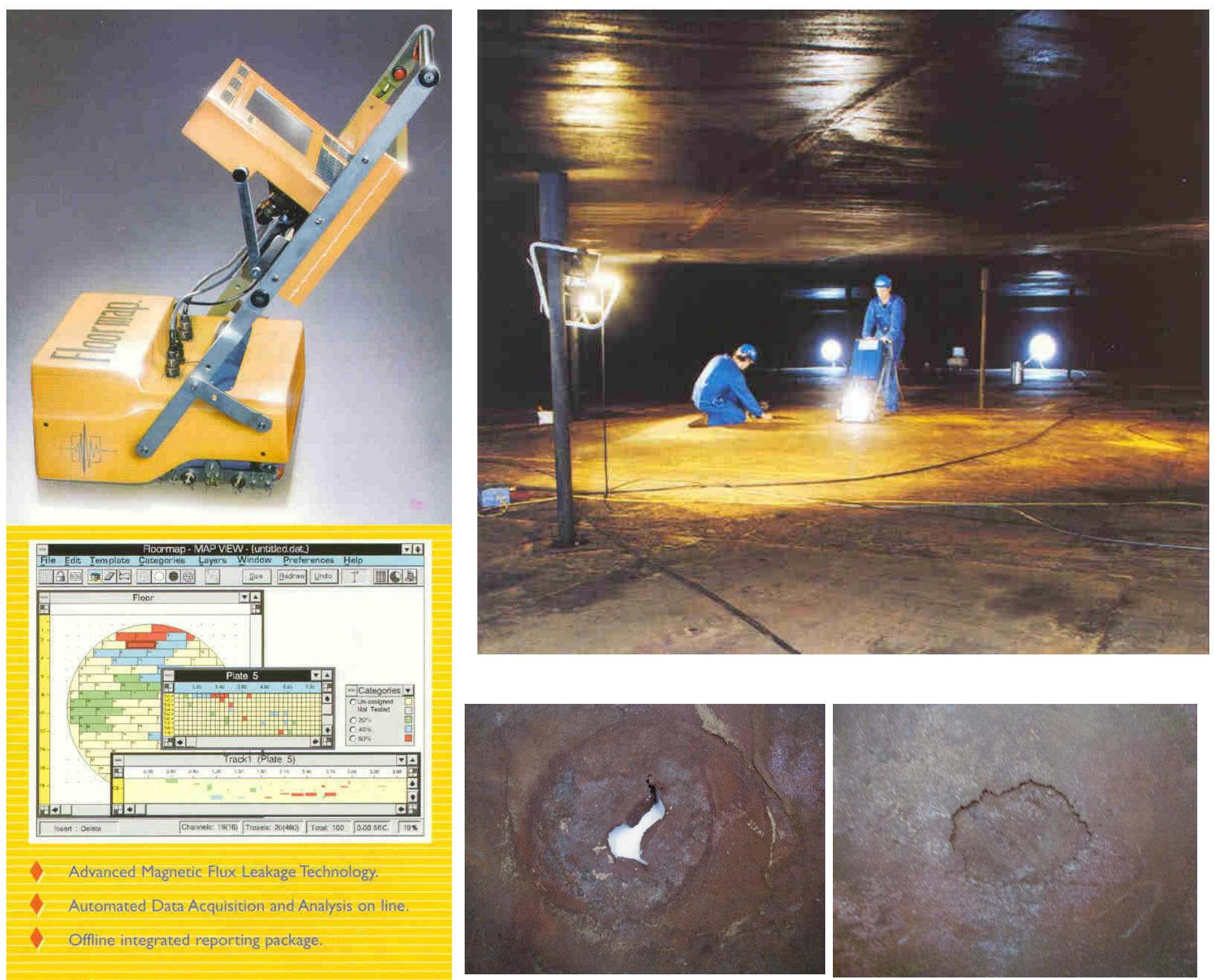

Manual tank floor inspection, underside corrosion defects 
EU FP5 ROBTANK: Mobile wall climbing robot enters through manholes on the floating or fixed roof of a tank to inspect tank floor and internal walls
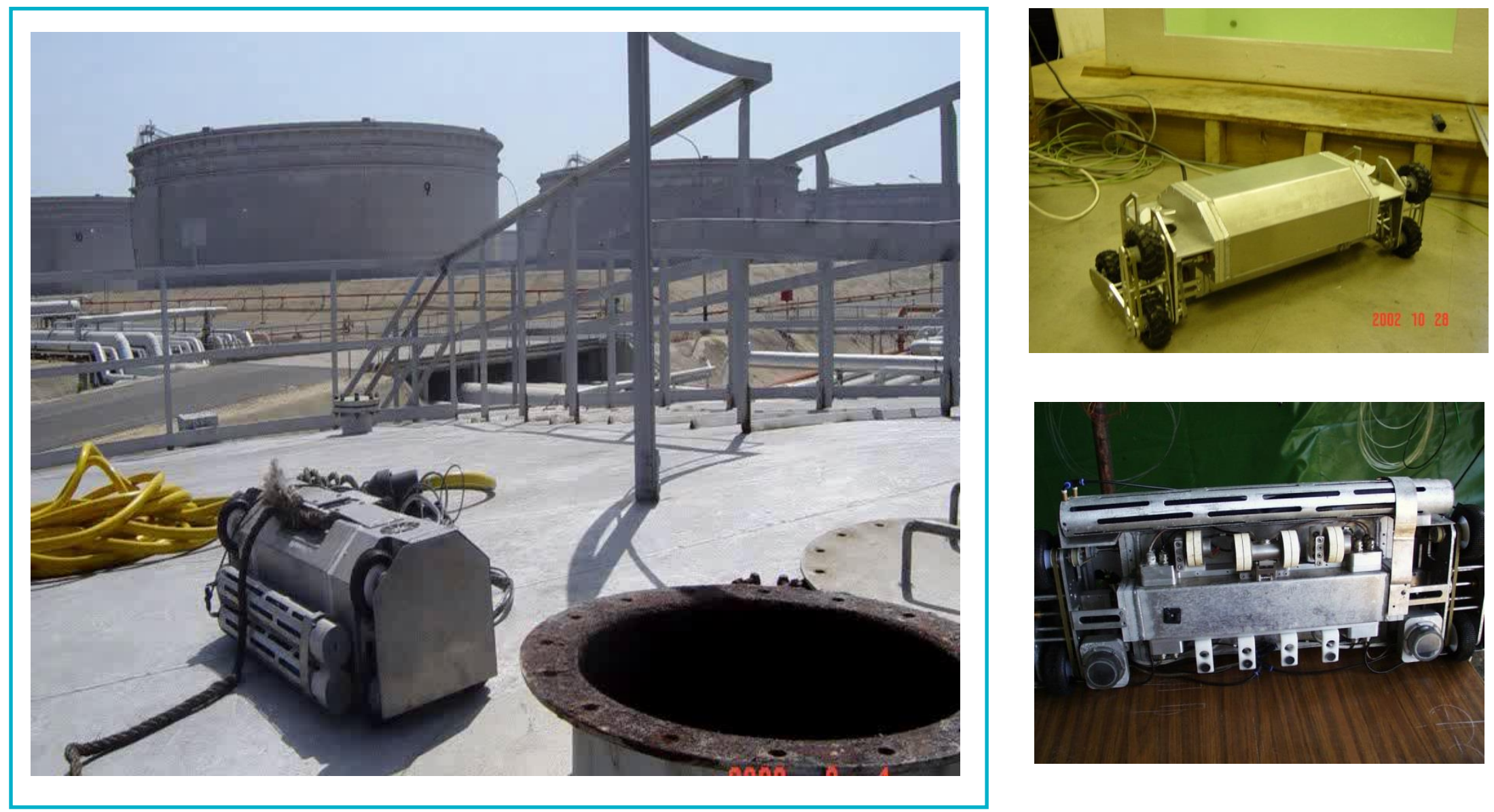

H2020 FTI TANKROB: Mobile robot to NDT tank floors with Phased Array Ultrasound - ATEX certification for Zone 1 operation 


\section{Mapping of floor defects using rotating bulk wave ultrasonic technique}
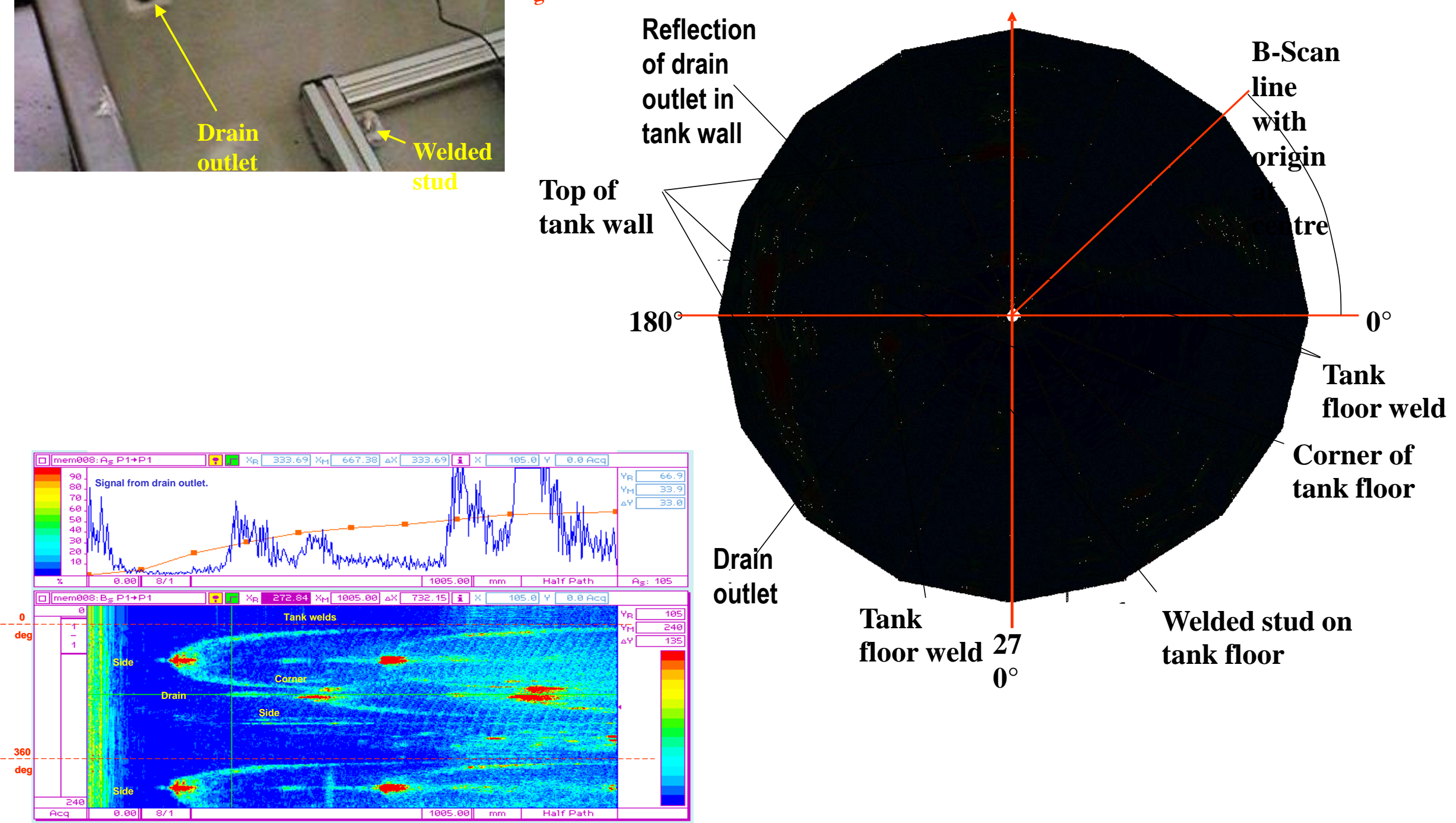
New InnovateUK funded project NAUTILUS: Bathyscaphic Robotic Floor Thickness Monitoring of Hazardous Liquid Storage Tanks

1. Active buoyancy control

2. Ultrasound NDT

3. Under liquid data communications

4. Zone 0 certification
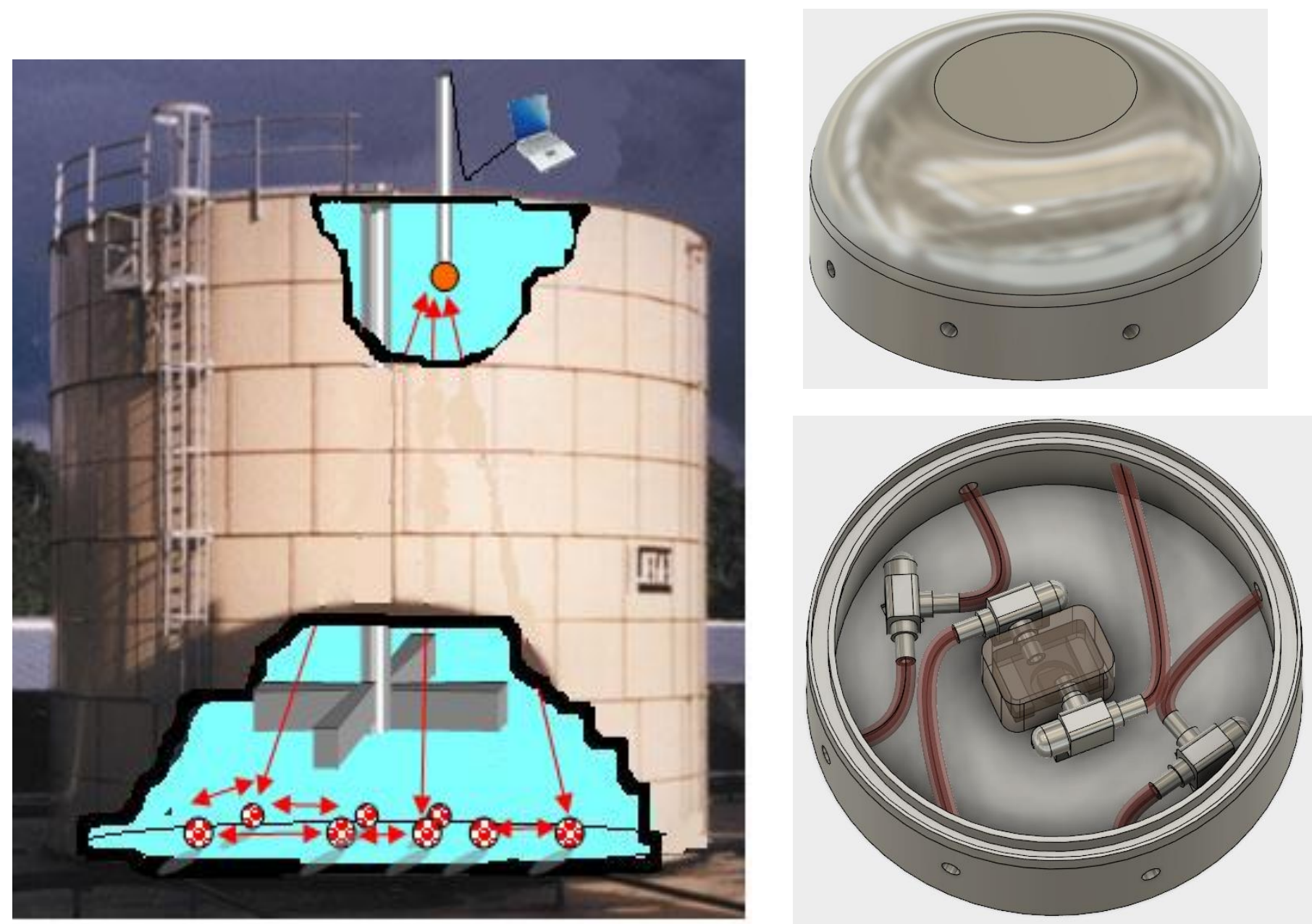


\section{Nuclear power plant}

\section{$>$ RPV Circumferential and Nozzle welds}

\section{$>$ Nuclear decommissioning}

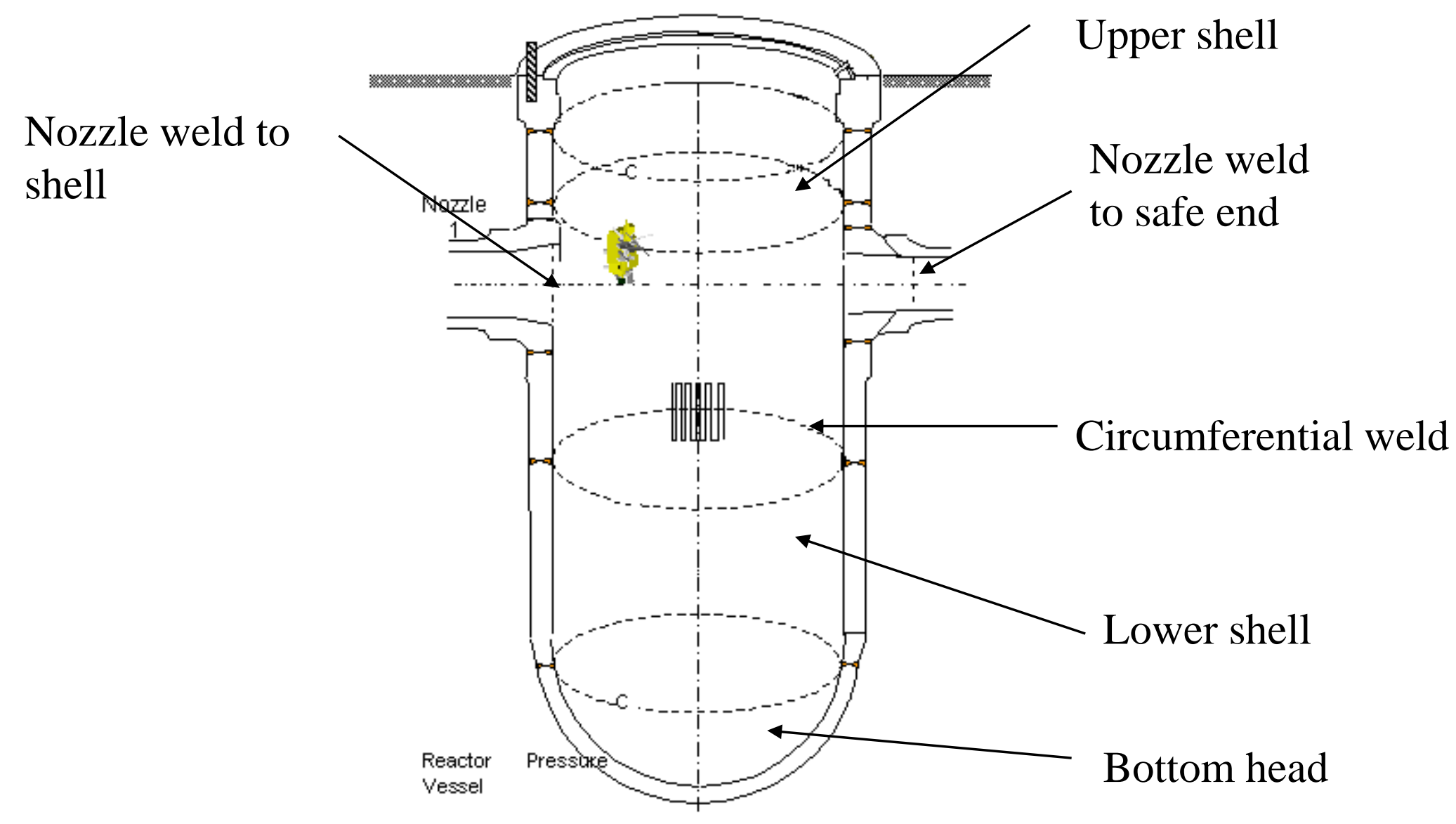


Current method of inspection uses large robots to do inspection - robot transported and assembled on site before immersion in RPV

- Require large and heavy robots with a central mast costing millions, manual set up time, tying up of polar crane needed for other tasks
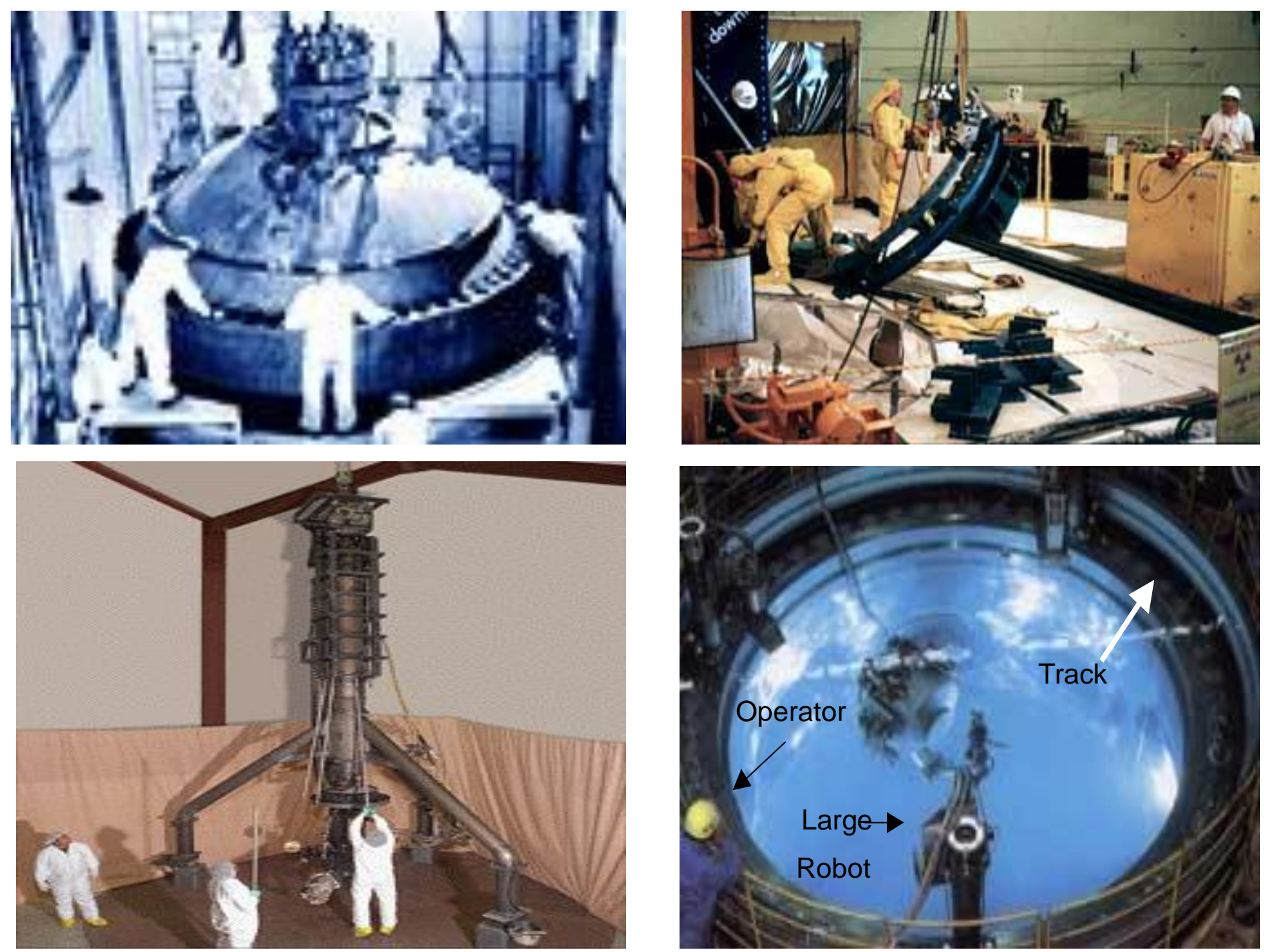
FP6-SME: RIMINI Development of new and novel low cost robot inspection methods for in-service inspection of nuclear installation

- Wall climber with nozzle crawler and scanning arm

- Neutrally buoyant climber+ nozzle crawler

- Positively buoyant climber, parked with suction cups

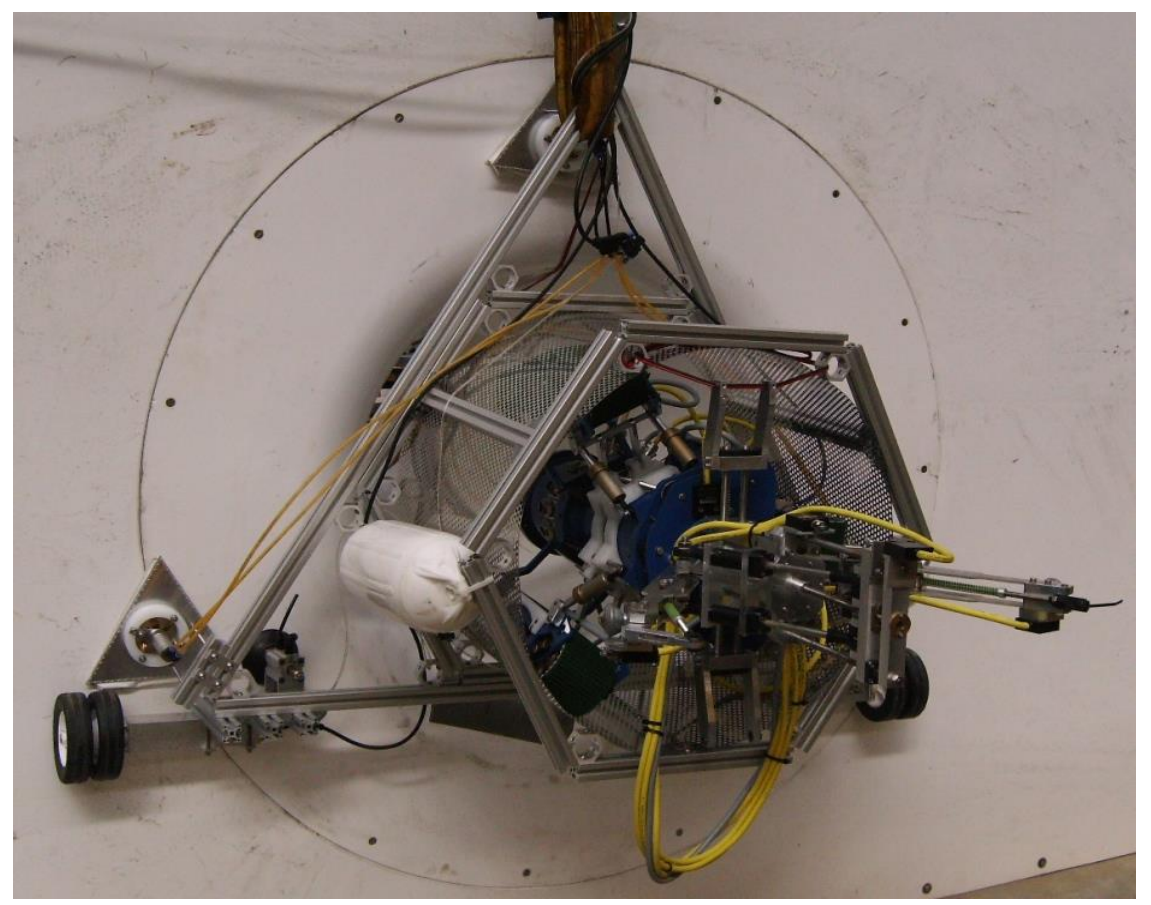



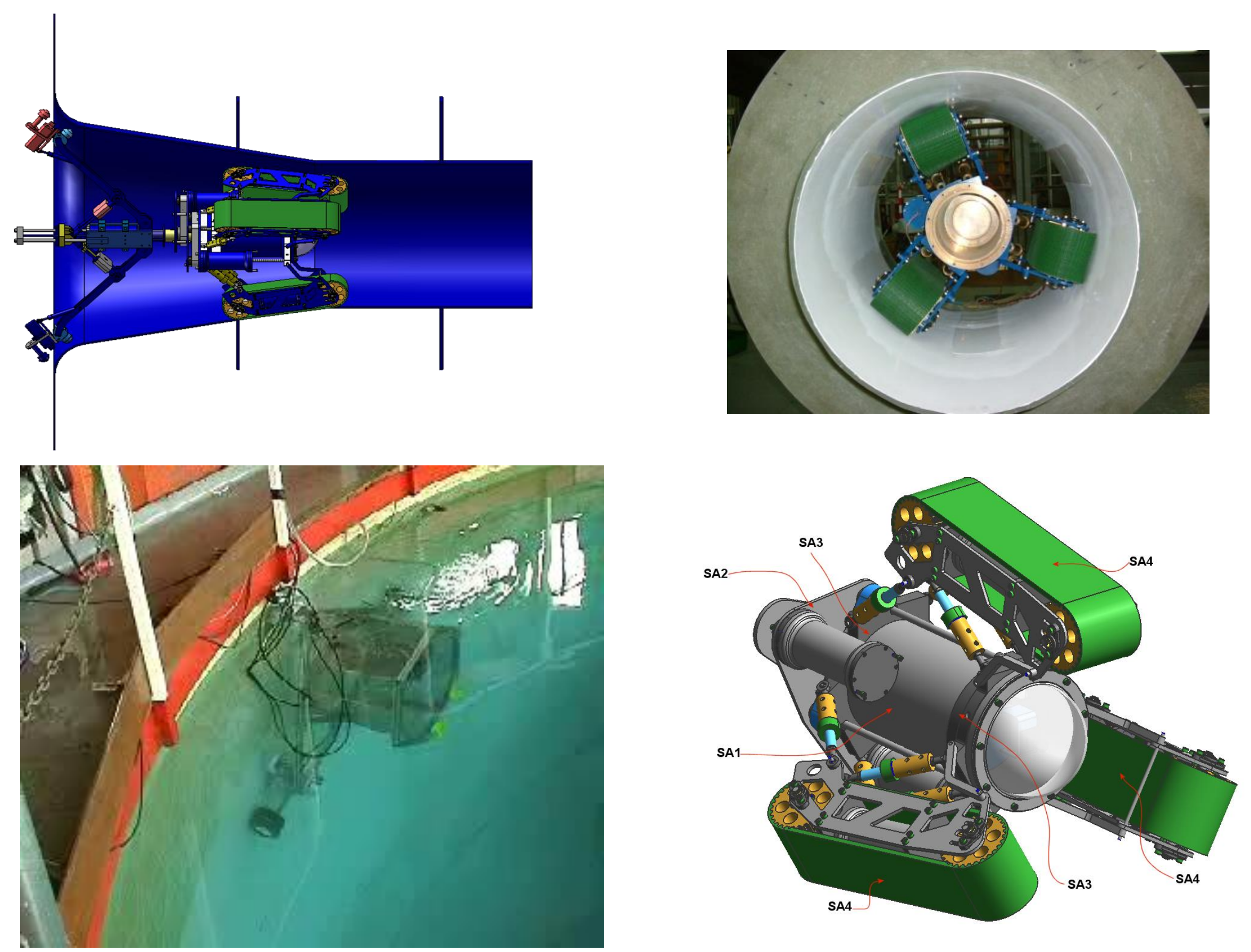
Decommissioning of the Sellafield nuclear reprocessing site

- 120 concrete buildings housing reprocessing cells, nuclear waste

- $£ 80$ billion to be spent in next 5 years to decommission

- 120 years to decommission site

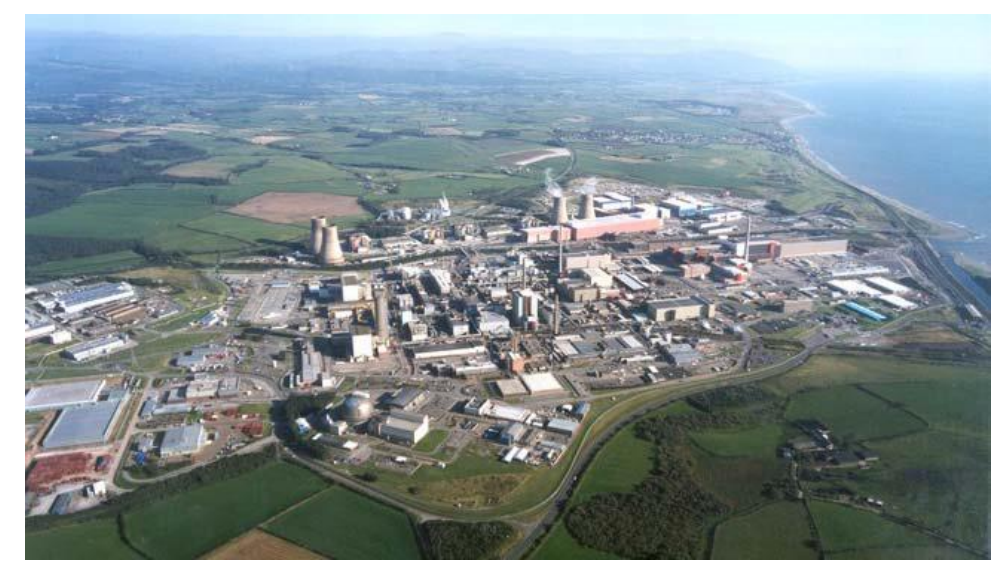

\section{Inspection (1) - Large Structures and Buildings}

- Faces/surfaces have safety implications for scaffold/rope access, remote measurements advantageous.

- Simple structural geometries suitable for ROV.

\section{Inspection (2) - Aerial Stacks}

- Concrete curved stacks over 100ft high, diameters $2-8 \mathrm{~m}$ at the base.

- Associated with ventilation systems for nuclear safety purposes. ROV minimises downtime if the internals are to be inspected by avoiding man access near to the outlet.

- ROV required to inspect the internals of an operational stack, with the associated air flows and velocities.

- External examination of stack expected. 


\section{Inspection 3 - Radiation Contaminated Reprocessing Cells}

- Store plant, vessels, pipework and other devices

- Concrete and rebar construction - clad with stainless steel 2-3mm thick with a transition part way up the wall (if not fully clad)

- Floors clad with stainless steel, demanding a high friction medium for traction. Accumulations of dusts/loose debris are possible

- ROV introduced via man-access door or cell wall penetration

- Walls 200 to $1800 \mathrm{~mm}$ thick

- Cell wall penetrations 150 to $200 \mathrm{~mm}$ in diameter
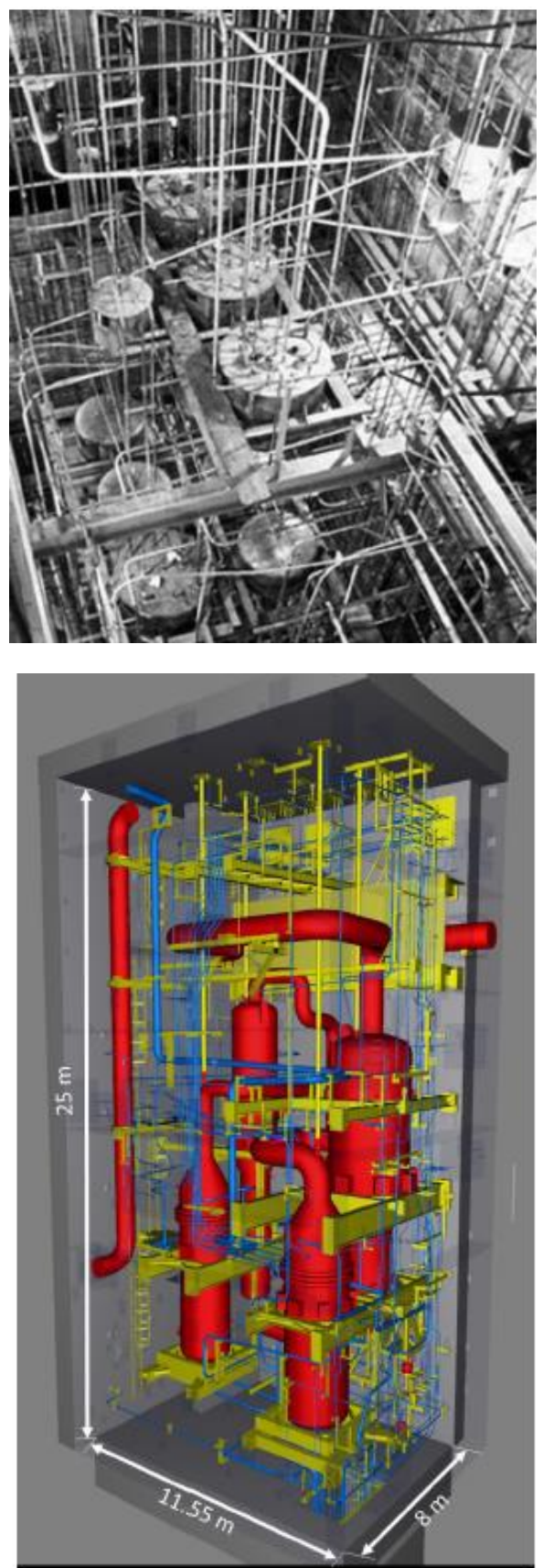
Climbing Robot for inspection of large concrete structures e.g.

- Stacks

- Radiation Cells

- Buildings

- Civil engineering structures

New InnovateUK project SIRCAUR
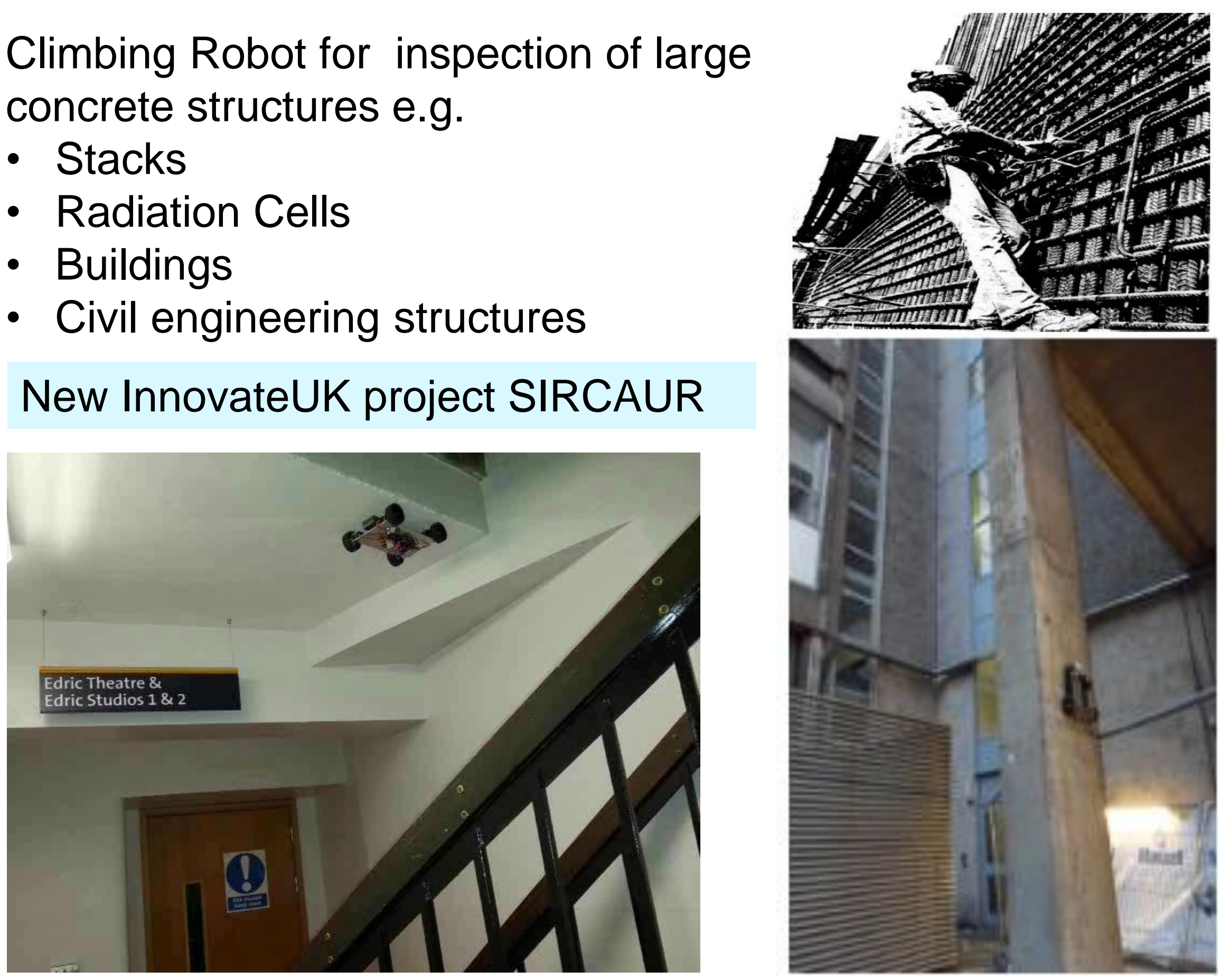


\section{Demonstration of STRONGMAN carrying TWI laser cutting tool}

for nuclear decommissioning - 21 September 2016

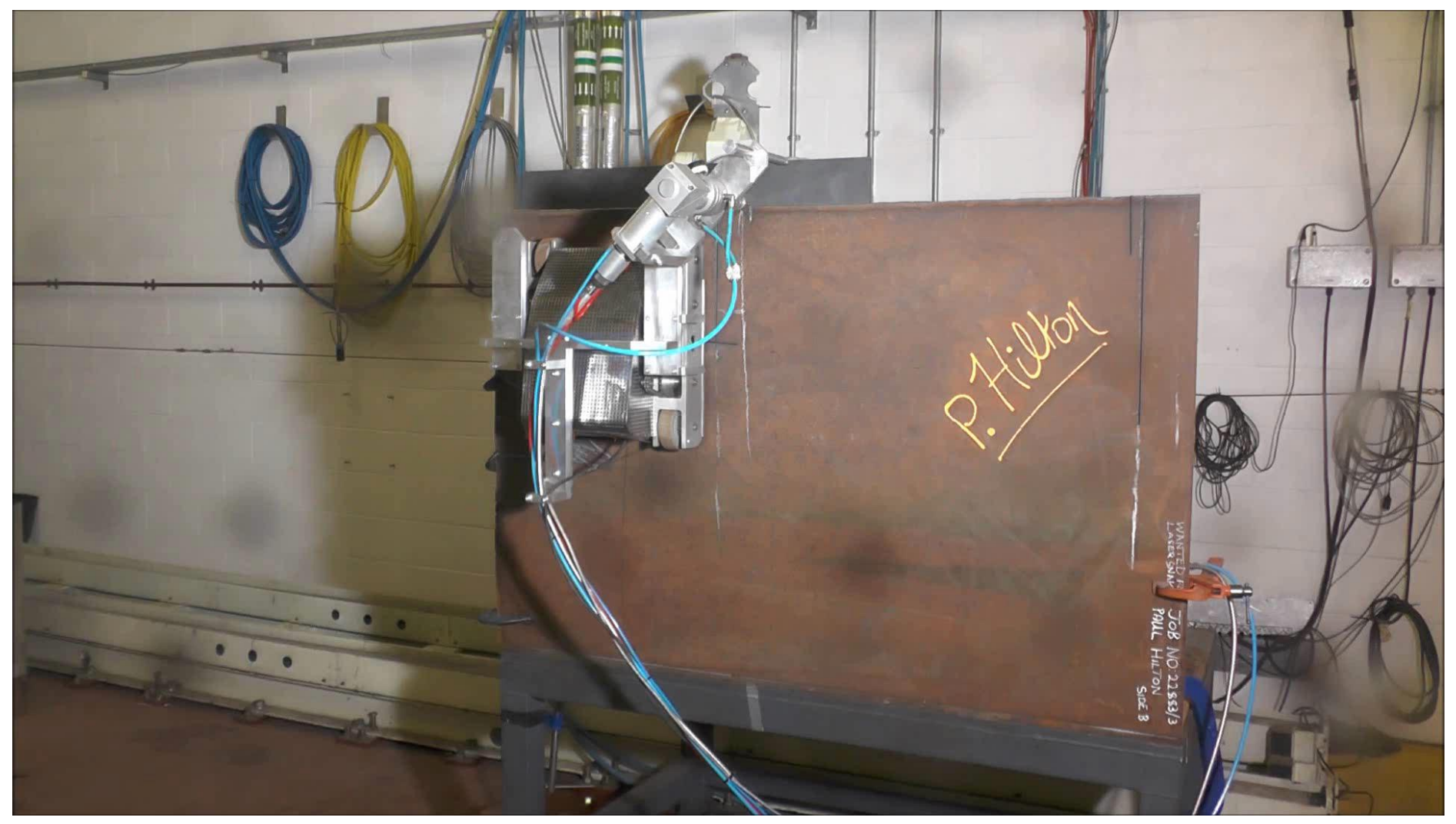

The Lasersnake2 R\&D project funded by the UK Technology Strategy Board, the Department for Energy and Climate Change, and the Nuclear Decommissioning Authority is using snake arms to deploy laser cutting heads 
Inspection of rows of rivets on aircraft wings and fuselage with a climbing robot
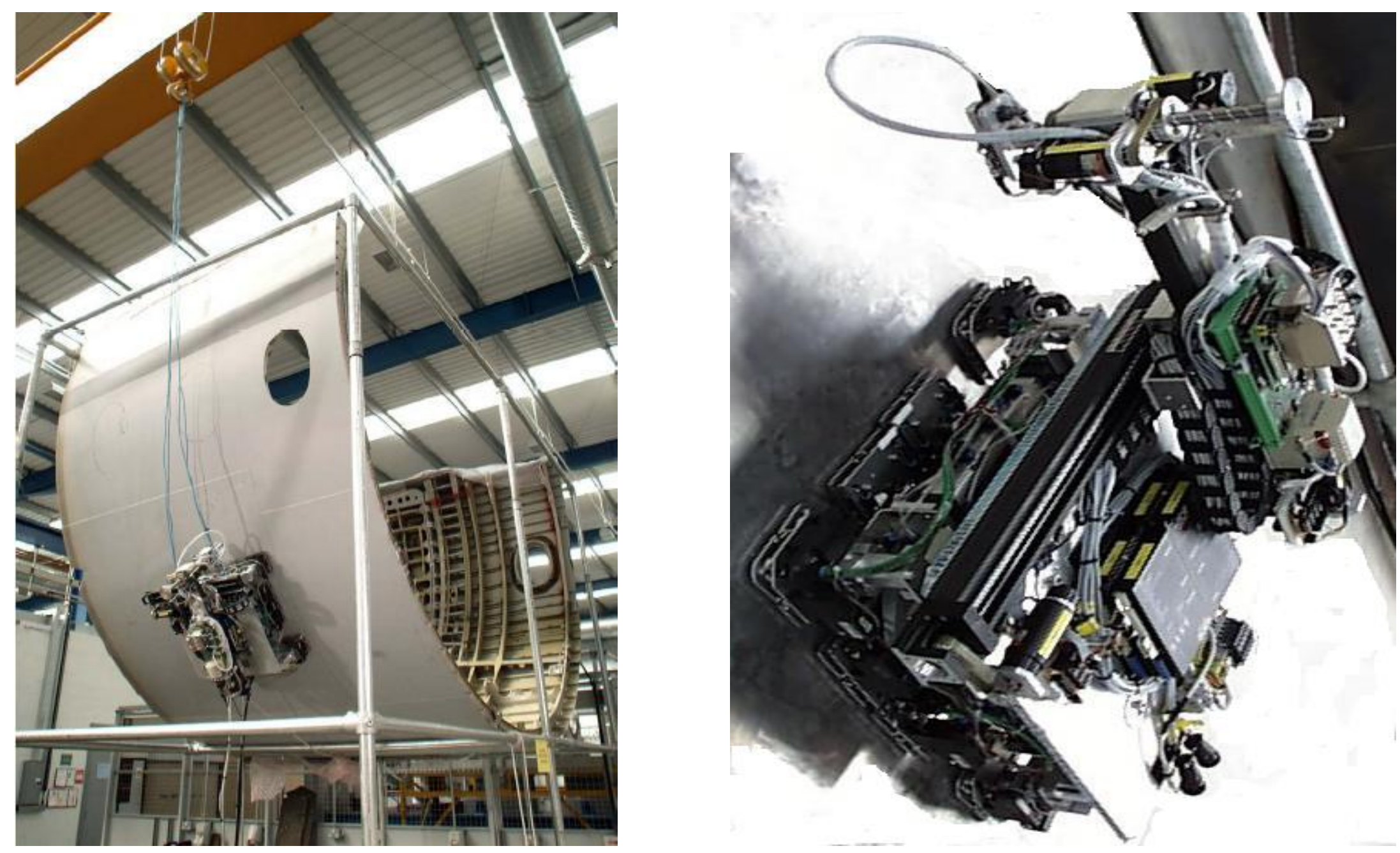


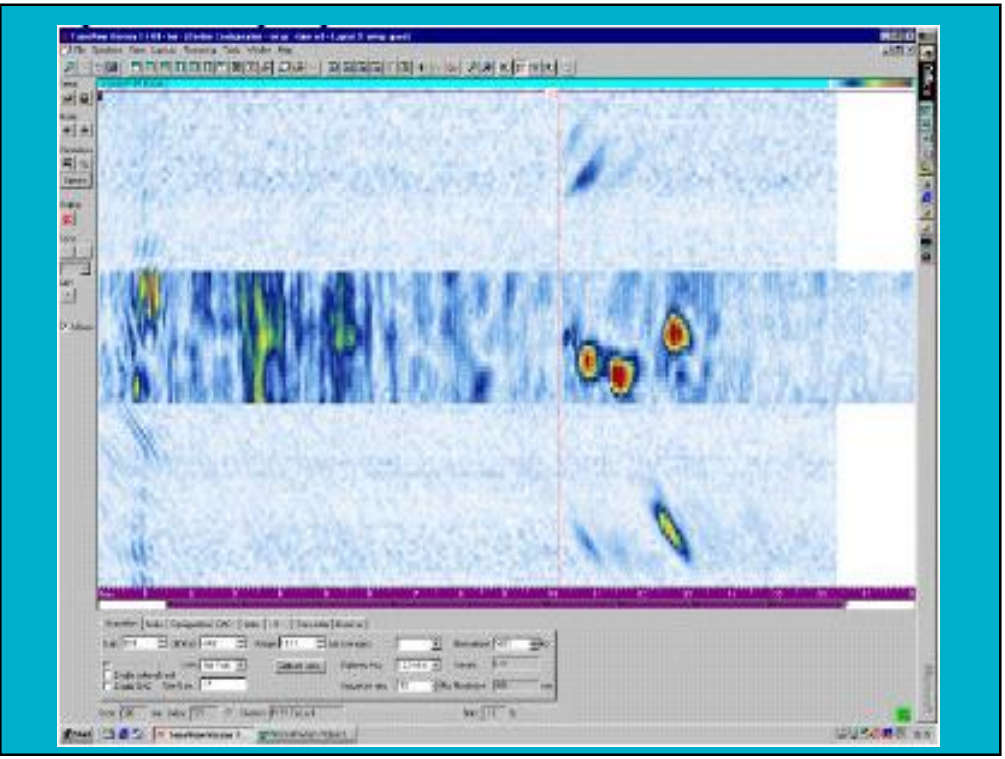

ULTRASONIC PHASED ARRAYS to inspect rivets on aircraft, ROBAIR project

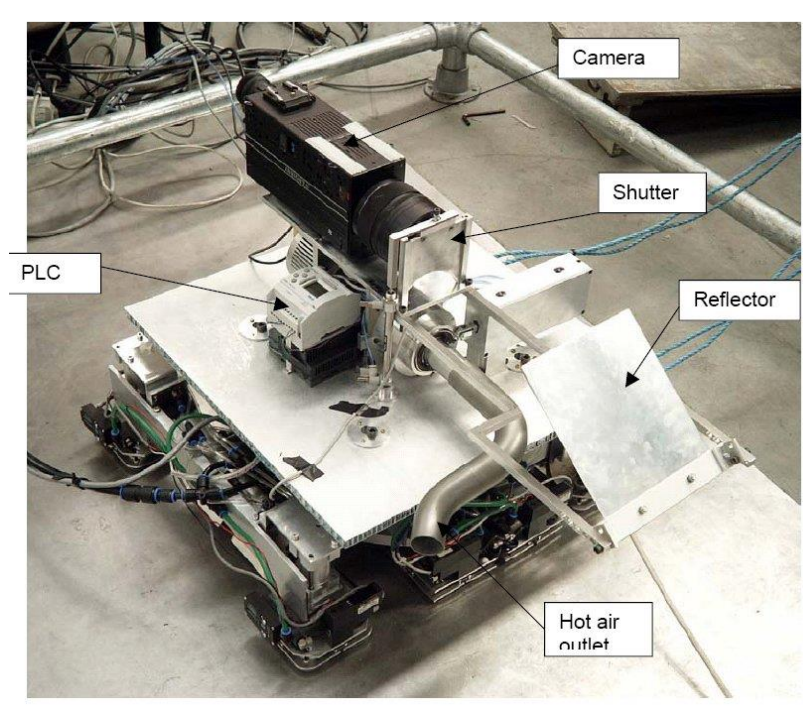

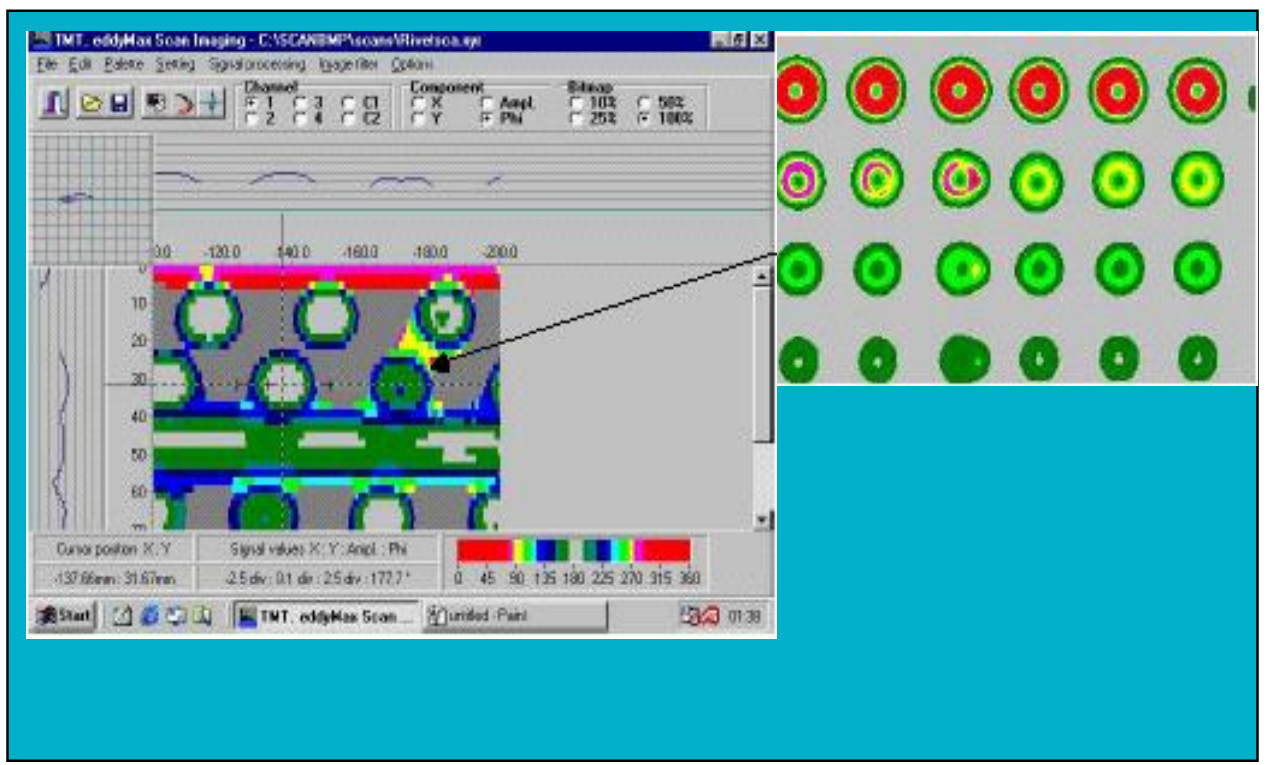

EDDY CURRENTS inspection of rows of rivets on the wings and fuselage of aircraft, ROBAIR project

Thermographic detection of loose rivets 


\section{Floating Production Storage of Oil (FPSO)}

Two tanks are

emptied, cleaned and inspected in 3-4 weeks with 60-70 man-days work and costs between $£ 30-40 k$.
Task: Inspect welds between strengthening plates and tank floor

- Outage required with cleaning of tank before inspectors can enter tank - problem of disposal of cleaning medium

- Eliminate outage by performing in-service inspection with mobile swimming robots or empty without cleaning and use amphibious robot

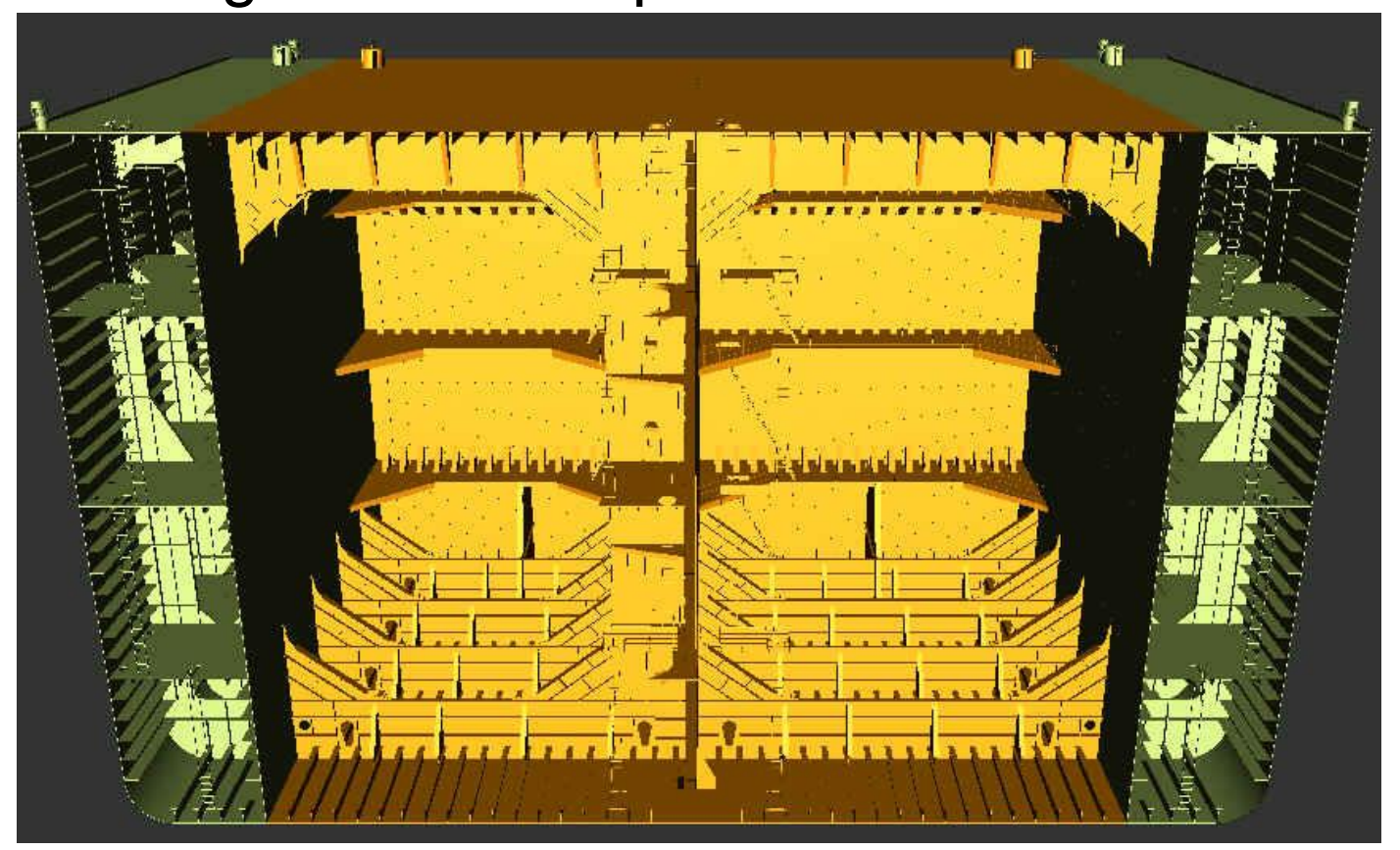


FPSO swimming and floor inspection robot to inspect tank floors and welds on strengthening plates

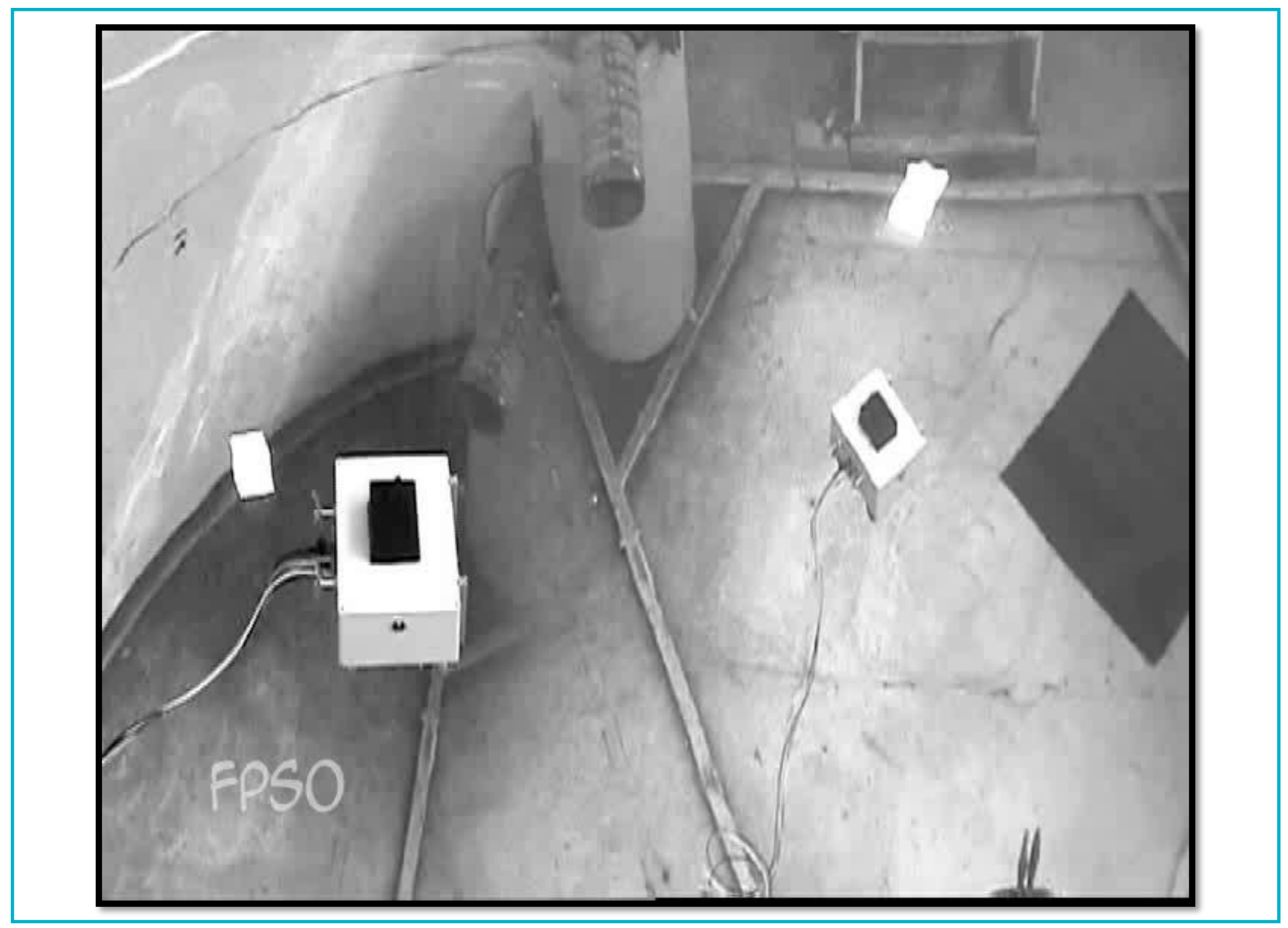


Horizon 2020-FTI Pilot2015

\section{RiserSure}

Rapid Integrity

Assessment of Flexible

Risers for Offshore Oil and Gas Installations

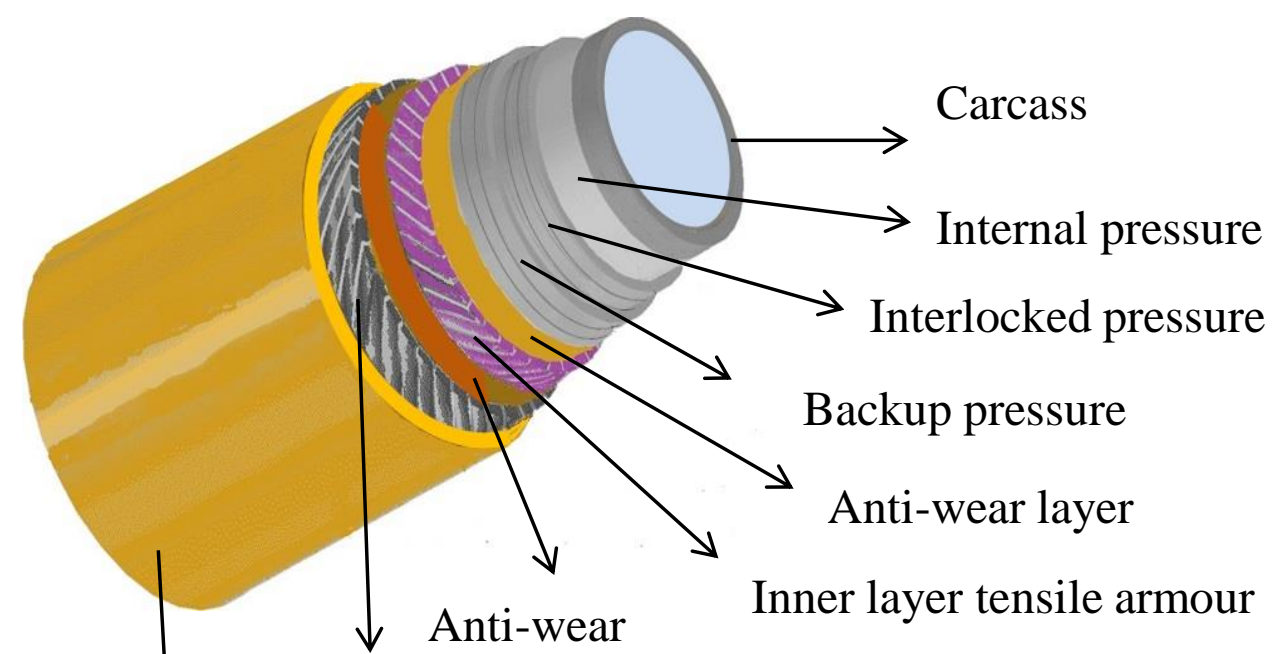
with radiography
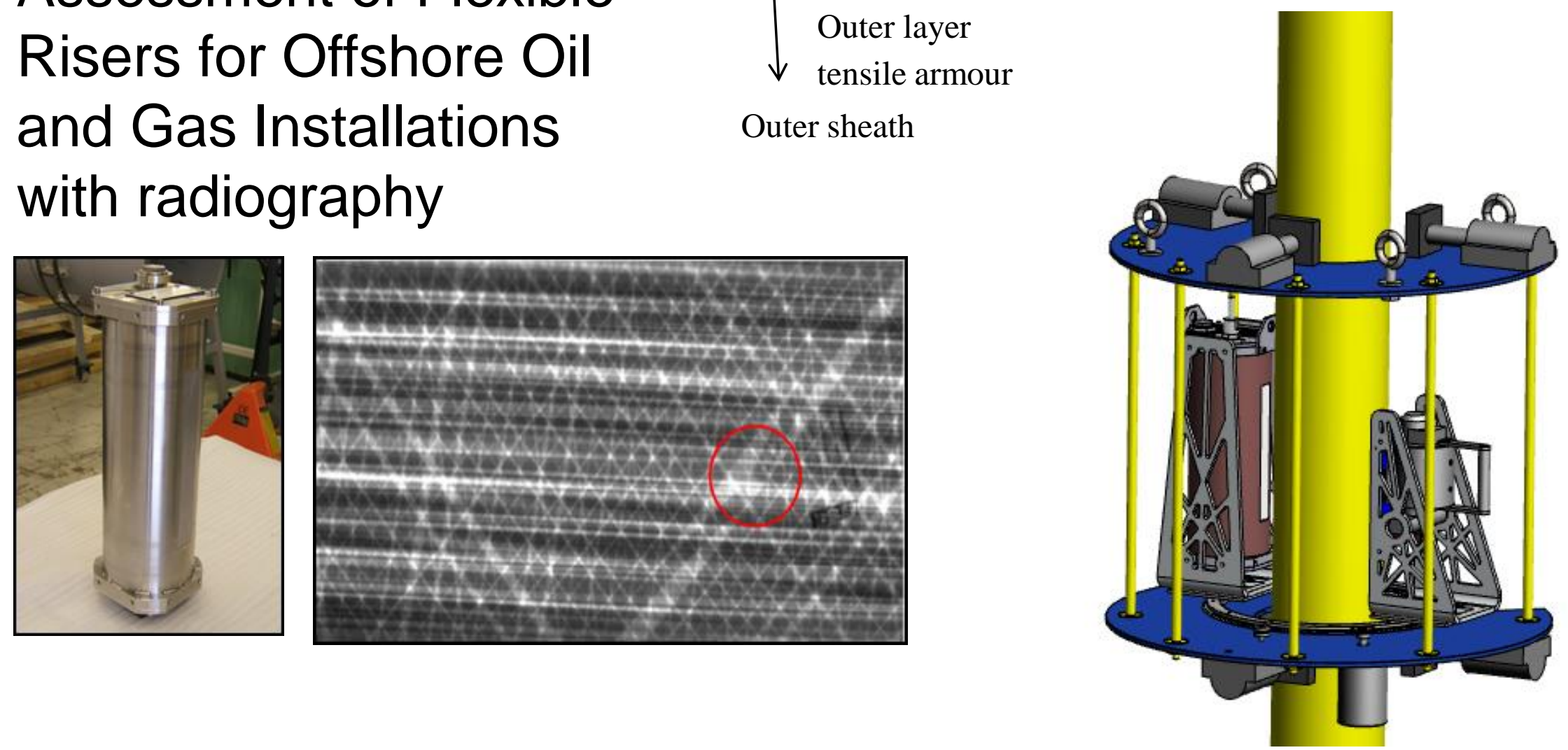
Mooring chains in shallow waters

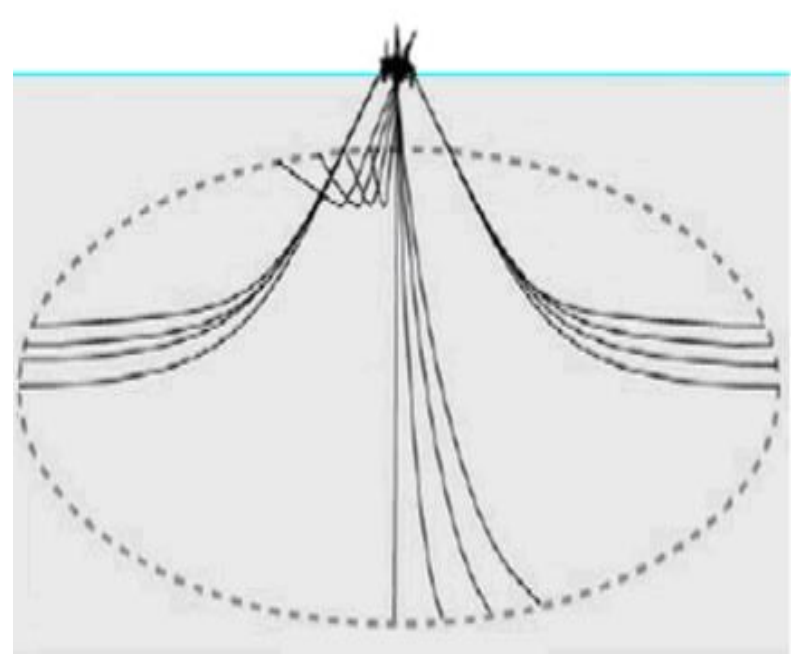

Mooring chains in deeper waters

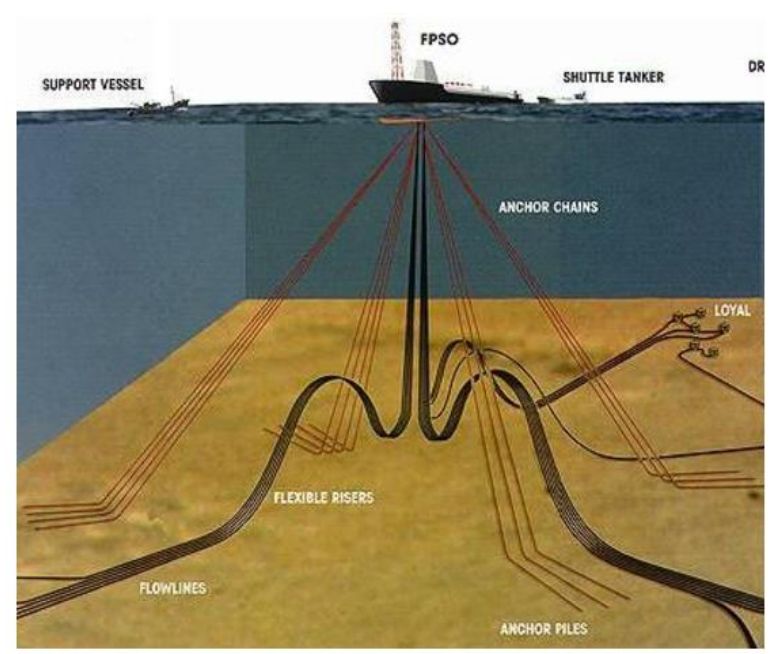

Link lengths $1 \mathrm{~m}$ to $0.7 \mathrm{~m}$

Dia $160-130 \mathrm{~mm}$

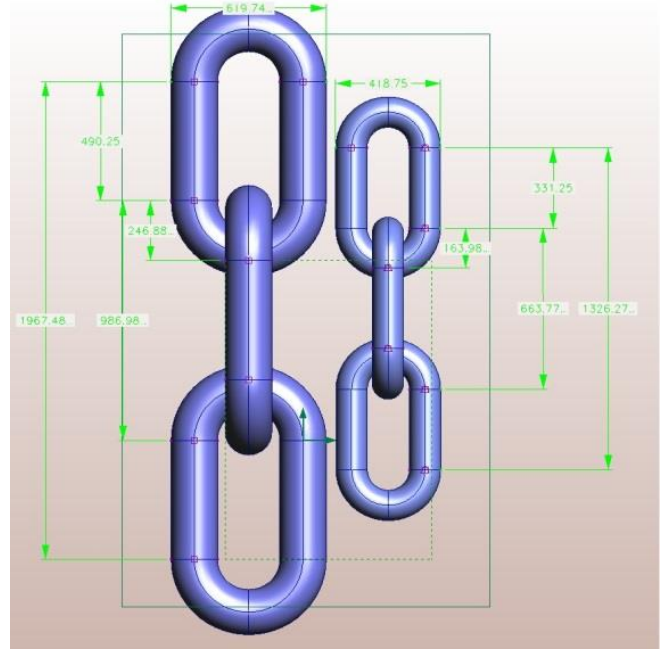

\section{MOORING CHAINS}

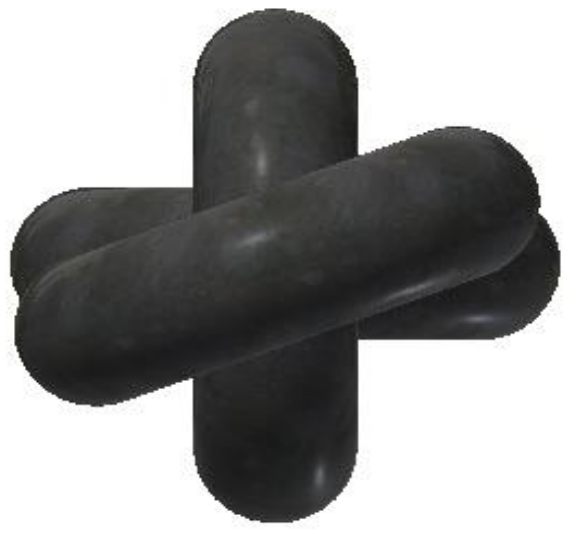

Link twist
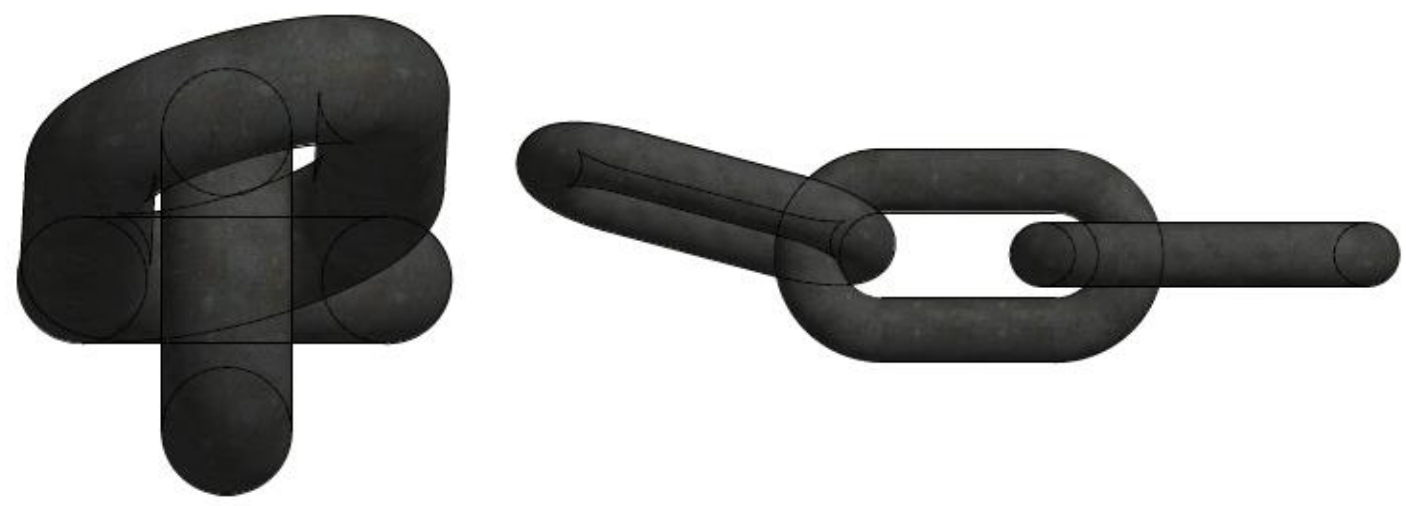

Link twist plus curve
Catenary curve in chain 

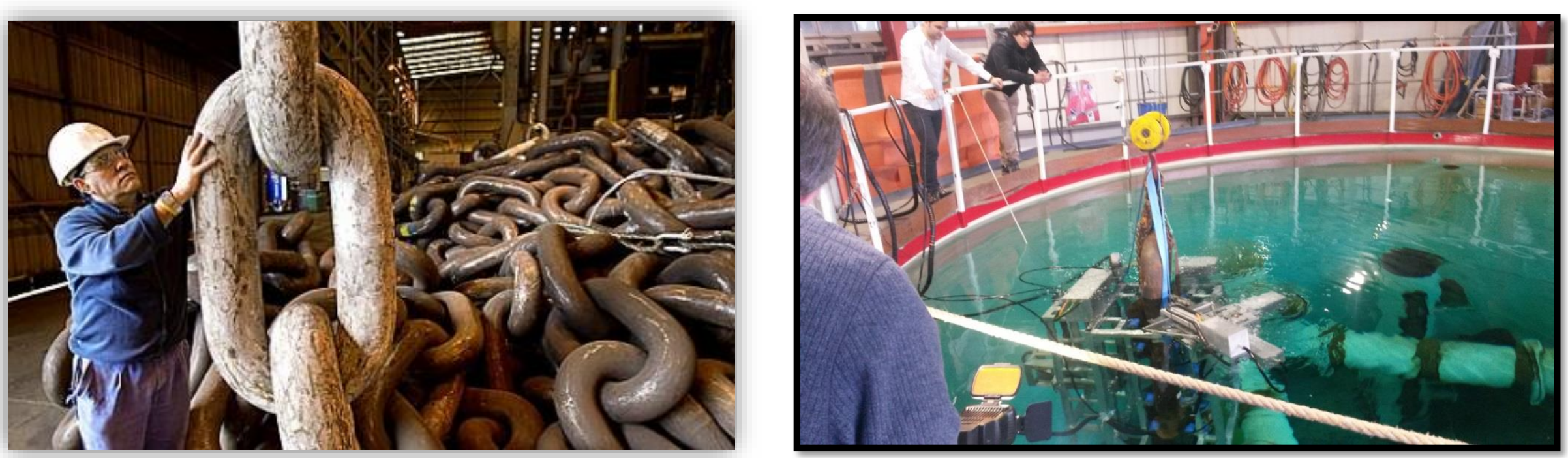

FP7-SME The MOORINSPECT PROJECT $\rightarrow$ InnovateUK/EPSRC project RIMCAW
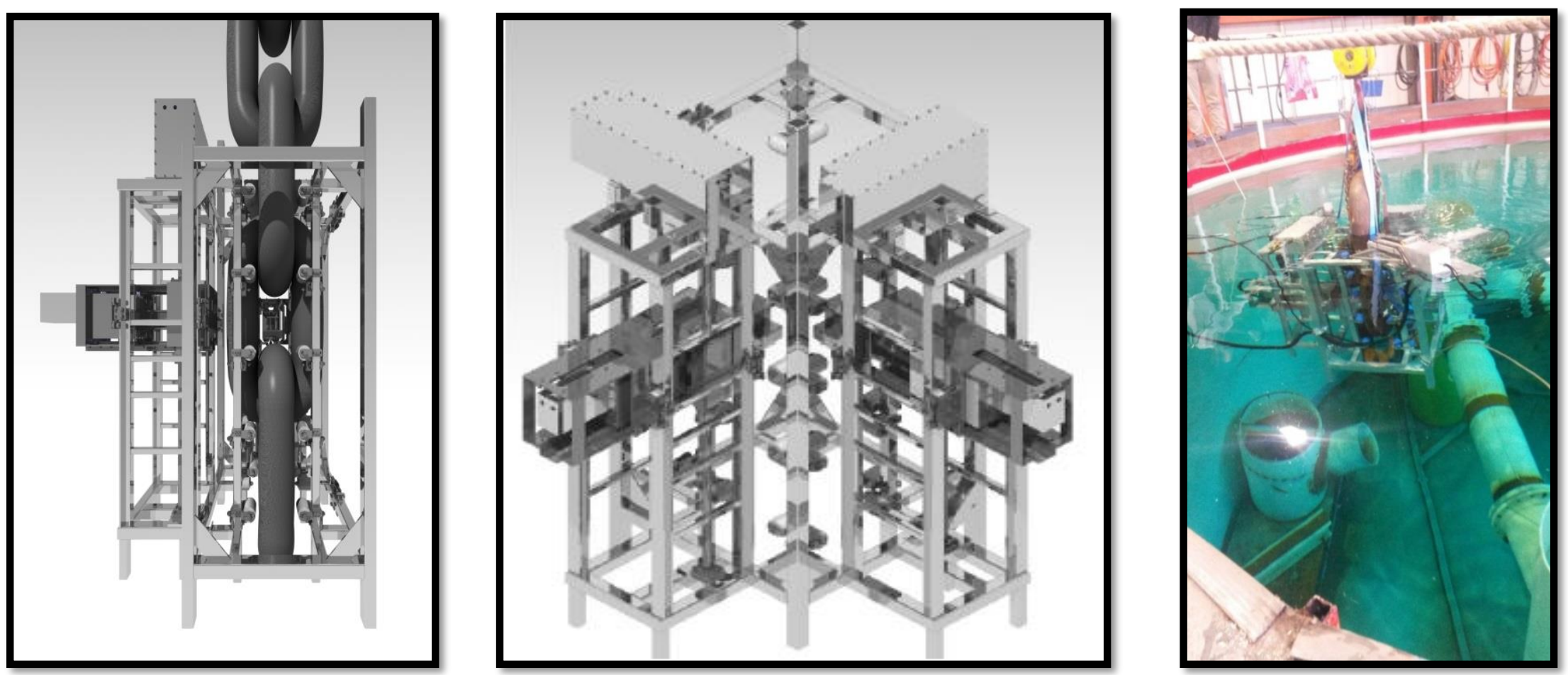
New InnovateUK project RIMCAW:

Robotic Inspection of Mooring Chains in air and water
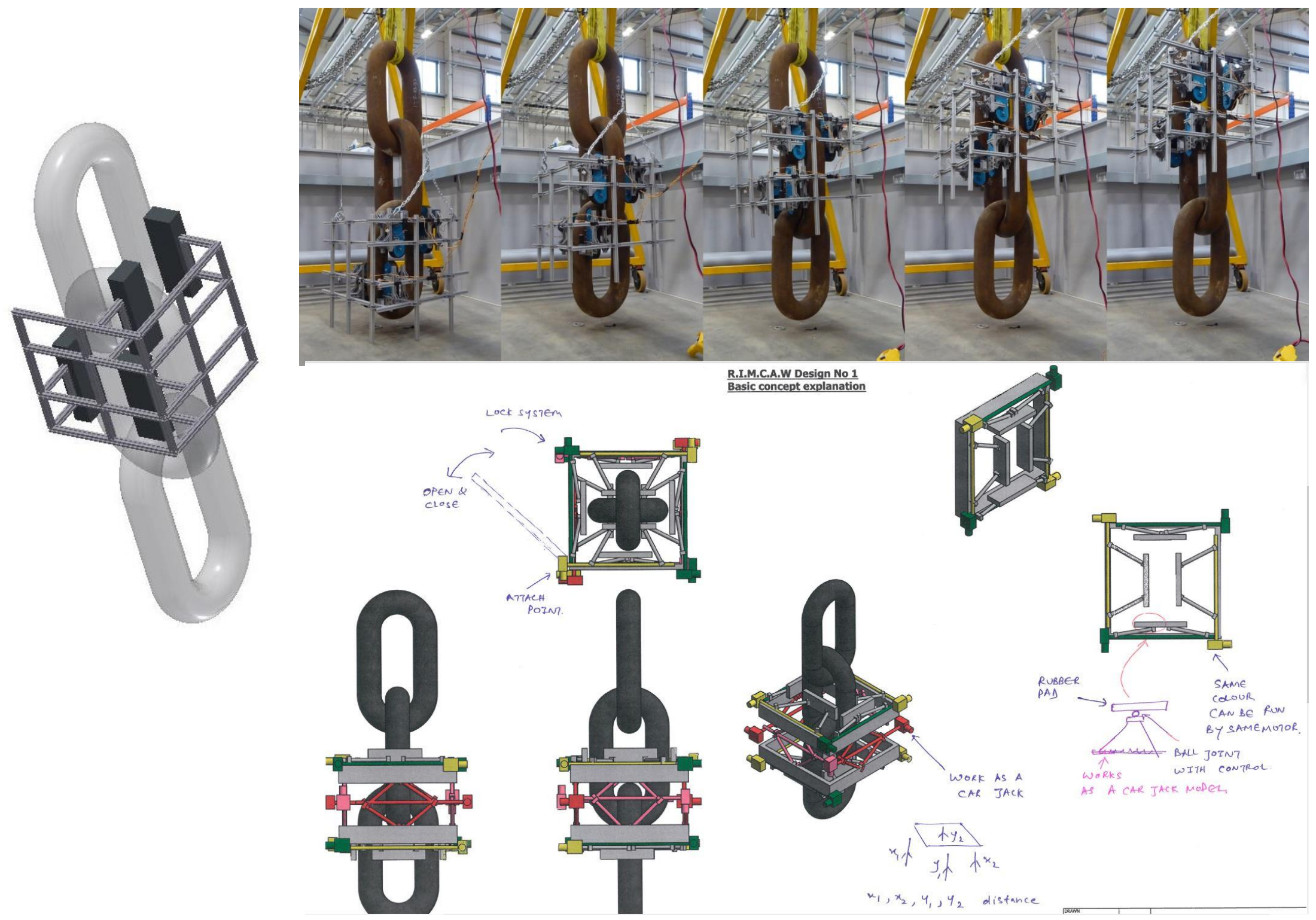
Climbing robots for monopile, wind turbine tower and blade inspection
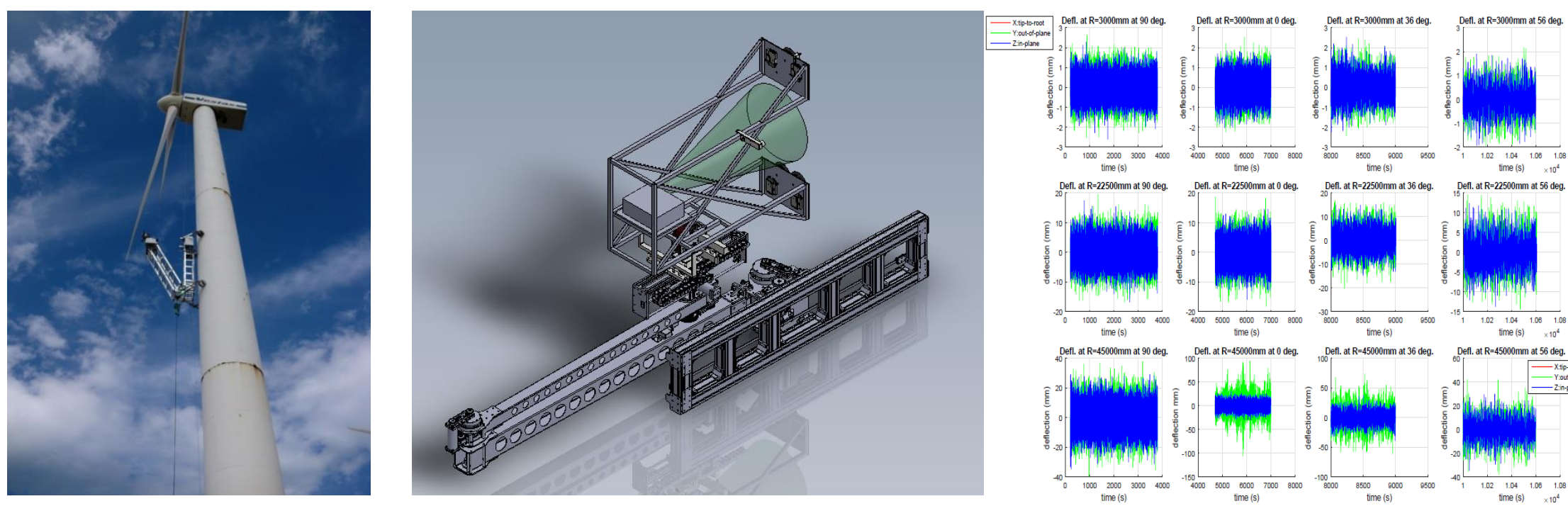

H2020 FTI project WINSPECTOR uses shearography to NDT blades

FP6 project to NDT blades uses X-ray computed tomography to NDT blades

New InnovateUK project RADBLAD $\mathrm{X}$-ray radiography of NDT blades with robots

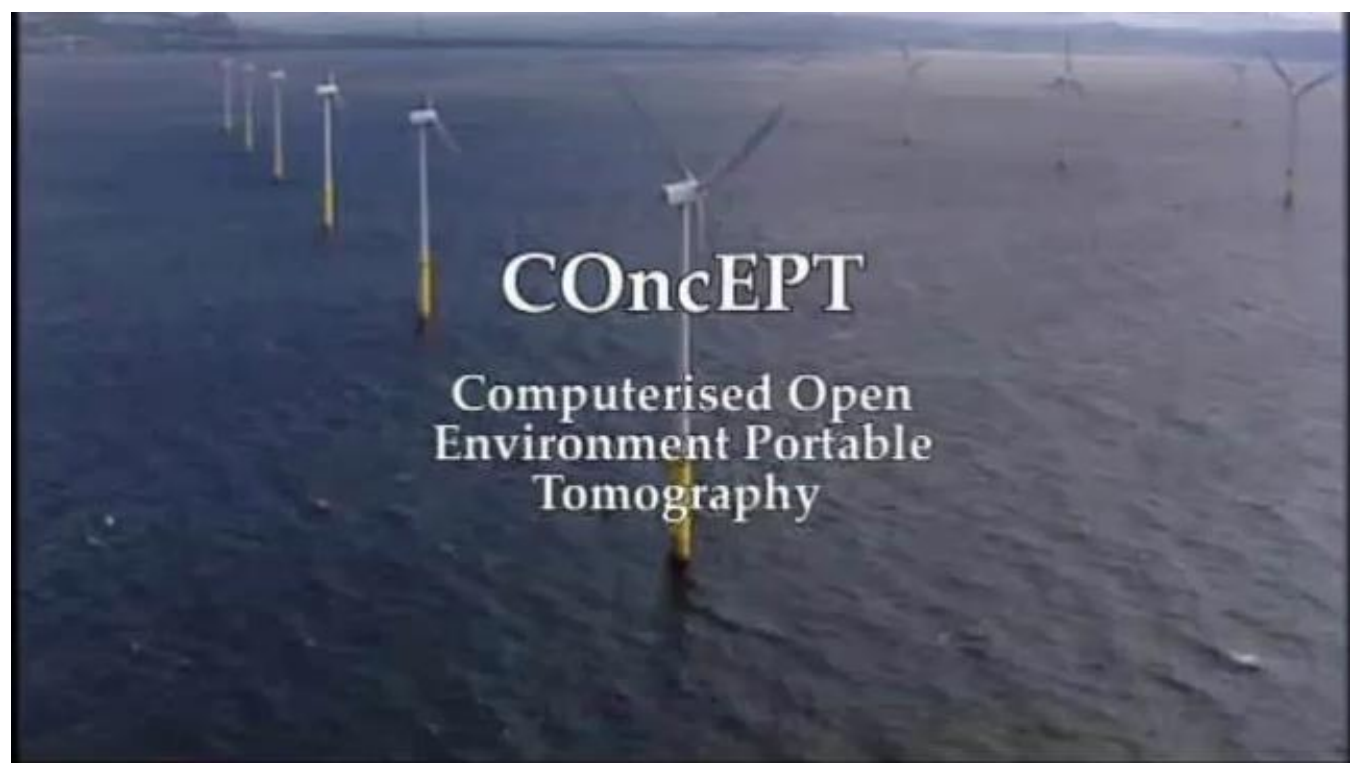


Pipeline inspection - pipe climbing robot
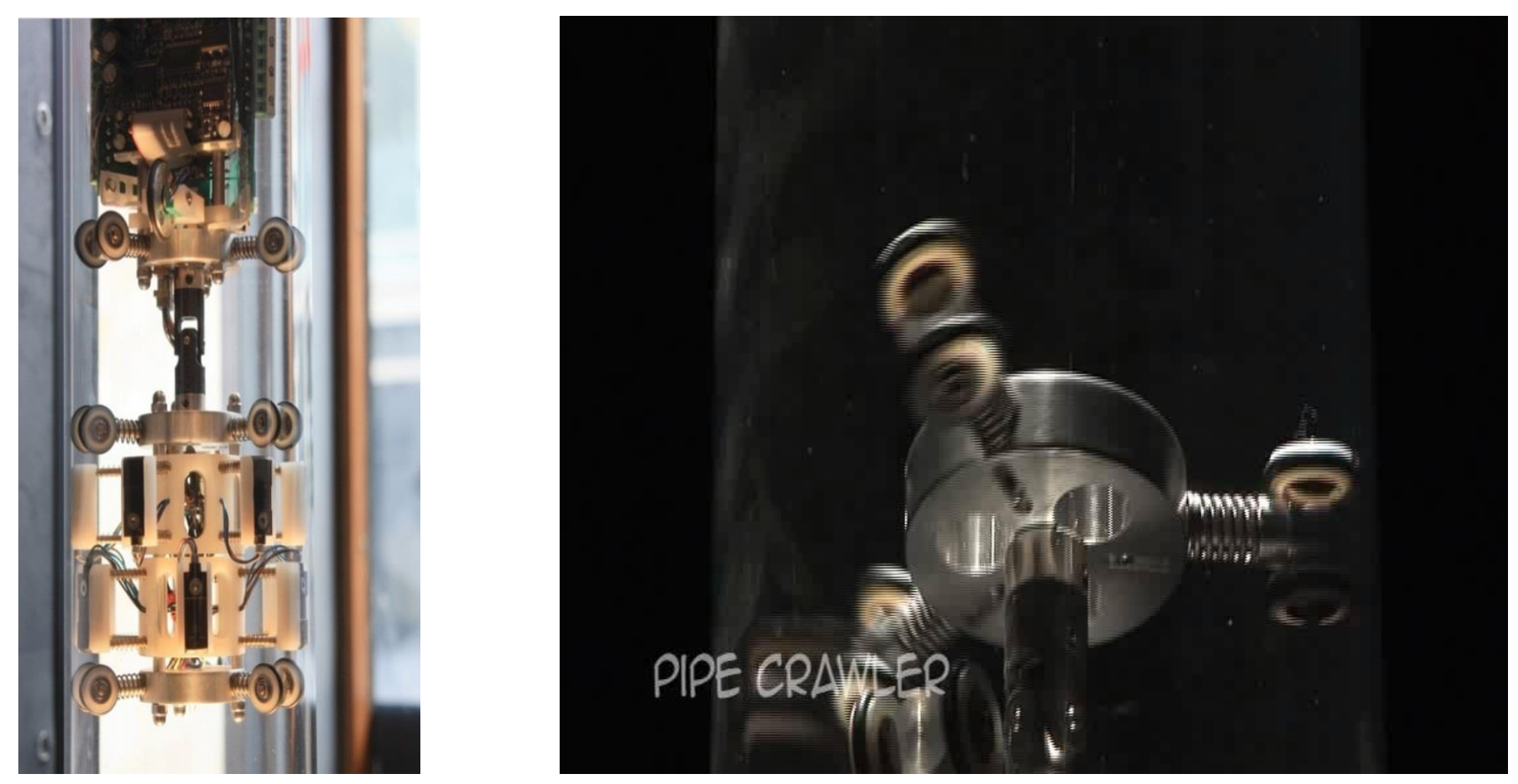

New InnovateUK project FSWBot to internally inspect and weld repair pipelines with robots 


\section{London South Bank}

Innavation Centre

\section{Conclusion}

Mobile robots that can access safety critical infrastructure located in remote and extreme environments promise to

$>$ Ensure the integrity of assets

$>$ Reduce inspection and maintenance costs

$>$ Reduce outage turn-around time/ perform in-service NDT

$>$ Increase worker health and safety and reduce fatalities 